\title{
LAS PINTURAS RUPESTRES DE COVA REMIGIA (Ares del Maestre, Castellón)
}

\author{
ELISA SARRIÁ BOSCOVICH \\ Universidad de Barcelona \\ A la memoria de Juan Porcar
}

\begin{abstract}
Cova Remigia", in Ares del Maestre (Castellón). The review is based on the use of a database, codifying each element and characteristics of the pictographs: tipology, conservation, technique, size, colour and other items which have allowed the observation of six different execution times of the panel.

Síntesis de las investigaciones llevadas a cabo en "Cova Remigia", Ares del Maestre (Castellón). Se ha realizado una revisión a partir de una base de datos, codificando los diferentes elementos y características de los pictogramas: tipología, conservación, técnica, tamaño y color, etc., que han permitido la identificación de seis momentos diferentes en la realización del panel.
\end{abstract}

El presente artículo viene a resumir algunos capítulos de la Tesis de Licenciatura que con el título «Las pinturas rupestres de Cova Remigia (Ares del Maestre, Castellón) (1), presenté en octubre 1989, en el Depto. de Prehistoria, H. ${ }^{a}$ Antigua y Arqueología de la Facultad de Geografía e Historia de la Universidad de Barcelona.

El objetivo principal de la Tesis de Licenciatura fue la revisión del estudio de este conjunto rupestre, realizado por $\mathrm{H}$. Breuil, H. Obermaier y J.

(1) La tesis de licenciatura está dividida en 7 capítulos: Historiografía, El conjunto de pinturas rupestres de la Cova $\mathrm{Re}$ migia, Datos estadísticos, Estratigrafía cromática, Contexto arqueológico, Conclusiones, Bibliografía y la reproducción de los dibujos o murales de las seis cavidades.
Porcar en el año 1935 y publicado por la Junta Superior de Excavaciones. Nuestro trabajo de investigación se basó en una ficha descriptiva de las figuras de cada abrigo, obtención de datos estadísti$\cos (2)$, sobre las características técnicas y temáticas, estudio de la estratigrafía cromática, repintes y superposiciones, con los cuales hemos podido obtener las líneas generales del proceso evolutivo que suscita a todos aquellos interesados en el estudio de estas manifestaciones.

(2) Para la obtención y manipulación de los datos se ha utilizado el método de trabajo de Ramón Viñas, publicado recientemente en la revista «Caesaraugusta», $n .^{\circ} 65-1988$, pp. 111-147 con el título «Programa y codificación de una base de datos para la documentación e investigación del arte postpaleolítico». 


\section{INTRODUCCIÓN}

En 1935 una excelente publicación, de carácter monográfico y modélica en su tiempo, dio a conocer uno de los conjuntos con pinturas rupestres prehistóricas más singulares de nuestro Prelitoral Mediterráneo: La Cova Remigia, al norte de la provincia de Castellón. En opinión de sus autores Joan Bta. Porcar, Hugo Obermaier y Henri Breuil, se trataba de: «...el sitio más importante que hasta la fecha se ha estudiado...", ya que para estos investigadores, este tipo de representaciones de estilo naturalista constituían: «El descubrimiento más importante que haya registrado en los últimos años la investigación científica acerca del hombre cuaternario en España...» (Porcar, Obermaier, Breuil 1935:5).

Hoy después de medio siglo, este mural, sigue ocupando un lugar importante entre los centros capitales de su estilo, característico por sus vivas y narrativas escenas que han sido comúnmente divulgadas con el nombre de "Arte Levantino». De todos modos y a pesar de su valor documental arqueológico no se volvió a llevar a cabo ningún otro estudio de conjunto, a excepción de la serie de trabajos temáticos sobre la iconografía de este lugar que realizó Juan Bta. Porcar y de algunos artículos en donde se ha tratado, de forma muy parcial, su temática.

En 1978, y durante el transcurso de una campaña de estudio, de las estaciones con arte rupestre prehistórico de la zona del Maestrazgo, organizada por R. Viñas, tuve la oportunidad de participar en la revisión de la primera y única copia existente hasta el momento de la Cova Remigia, ejecutada por $\mathbf{J}$. Bta. Porcar. En este primer trabajo se comprobó la presencia de otros detalles y figuras inéditas, asi como otras en parte destruidas o desaparecidas. De todas estas observaciones surgió la idea de llevar a cabo una nueva reproducción del mural, con el fin de obtener un estado actualizado del conjunto.

La finalidad de este trabajo de investigación ha sido por una parte la realización de una copia actualizada del conjunto, integrada por 6 cavidades, y por otra el estudio del proceso evolutivo a partir de las superposiciones cromáticas (3).

(3) La copia ha sido realizada a tamaño natural, partiendo de un archivo fotográfico de unas 1.000 transparencias y ejecutado sobre soporte cartulina (120 gramos), y que han ocupado unos $40 \mathrm{~m}$. (en hojas de $70 \times 100 \mathrm{~mm}$.).
Las conclusiones de este trabajo consisten en un ensayo sobre la cronología relativa de las diversas fases pictográficas y de una serie de reflexiones sobre las mismas, las cuales parten de las superposiciones que van marcando la estratigrafía cromática. Esperamos que un futuro no muy lejano, puedan establecerse conexiones, con los niveles arqueológicos de Cova Fosca con los cuales creemos existe una estrecha relación.

Uno de los resultados de la revisión de este friso ha sido el hallazgo de 285 figuras inéditas, las cuales sumadas a las ya conocidas alcanzan el total de 759 elementos pictográficos, convirtiéndose en uno de los conjuntos numéricamente más importante de su estilo.

Por último, quisiera agradecer a todas aquellas personas que de un modo u otro me han ayudado a lo largo de mi estudio y han hecho posible la realización del mismo. En especial a Federico Barreda, guarda del conjunto rupestre, por su ayuda durante todo el trabajo de campo; a Ramón Viñas por su archivo fotográfico y acceso a su método de estudio; a la Dra. M. ${ }^{\text {a }}$ Lluisa Pericot quien dirigió los primeros pasos de este trabajo; a mi director Dr. José M. ${ }^{a}$ Fullola por aceptar con agrado la dirección de este estudio, y a la Conselleria de Cultura Educació i Ciencia de la Generalitat Valenciana, por facilitarme el permiso para la comprobación de los últimos detalles.

\section{ANTECEDENTES}

Las pinturas rupestres de la Cova Remigia, fueron descubiertas o conocidas por el masovero del «Mas de Remigia o Modesto» M. Fabregat, el cual nunca les había atribuido ninguna importancia. Fue Gonzalo G. Espresati en 1934, con motivo de una cacería, visitó las pinturas y reconoció la semejanza con las del Barranco de La Valltorta (TírigAlbocàsser) y pocos días después invitó a J. Porcar y a E. Codina, haciéndose cargo de los primeros trabajos. En septiembre de aquel mismo año, J. Porcar se comunicó con $\mathrm{H}$. Obermaier para que colaborara en el estudio científico de la Cova Remigia y otras actividades.

El 26 de octubre de 1934, H. Obermaier y H. Breuil visitan la cavidad y con ayuda financiera de la Junta Superior del Tesoro Artístico, se inician los trabajos de documentación y estudio de las pinturas. 
El primer artículo aparecido se debe a J. Porcar «Pinturas rupestres del Barranc de Gasulla» (Porcar 1934), realizando las primeras descripciones de las pinturas, dibujos y fotografías de E. Codina. Un año después, el mismo autor, da a conocer otras cavidades situadas en los alrededores del barranco de la Gasulla «Noves pintures rupestres en el terme d'Ares» (Porcar 1935).

Paralelamente $\mathrm{H}$. Obermaier, publicaría algunos artículos de carácter divulgativo «Nuevas pinturas cuaternarias en la región de Castellón de la Plana», apoyando la edad Peleolítica de las mismas (Obermaier 1935) y «Las pinturas rupestres del Barranco de Gasulla» (Obermaier 1936). En 1935 J. Porcar, H. Obermaier H. Breuil dan a conocer su estudio sobre la Cova Remigia «Excavaciones en la Cova Remigia (Castellón)» (Porcar, Obermaier, Breuil 1935), constituyendo el mejor estudio del conjunto realizado sobre el mural de la Cova Remigia, tratando puntos importantes como: consideraciones generales de la zona, la cueva y sus pinturas, la cronología, significación, impresiones de carácter técnico sobre la composición de las escenas y otras consideraciones acerca del arte levantino.

En 1942, F. Álvarez-Ossorio publica en el Boletín de la Real Academia de la Historia un artículo «Covacho con pinturas rupestres en el Barranco de la Gasulla, en Ares del Maestre (Castellón de la Plana)», en el que propone que se declare monumento histórico-artístico, a los abrigos con pinturas y que se proceda y logre la conservación de tan interesantes obras pictográficas (Álvarez-Ossorio 1942).

Años más tarde J. Porcar reanuda en solitario los estudios sobre Cova Remigia y los abrigos próximos, dentro del término de Ares del Maestre, publicando en esta segunda fase un gran número de artículos como: «Sobre las pinturas rupestres de Ares del Maestre» (Porcar 1943), analizando los utensilios de caza representados; «El trazo por impresión directa y el trazo caligráfico en el arte rupestre en Ares del Maestre» (Porcar 1943), observando dos momentos en la ejecución del conjunto de Cova Remigia; «El valor expresivo de las oblicuas en el arte rupestre del Maestrazgo", tratando sobre la práctica de las líneas oblicuas y el aprovechamiento del relieve rocoso (Porcar 1944); «Pinturas rupestres arrancadas de Cova Remigia», poniendo de manifiesto la destrucción de alguna de las pinturas (Porcar 1944).

A partir de 1945, J. Porcar inicia una serie de trabajos bajo el título «Iconografía rupestre de la
Gasulla y Valltorta» en los que recoge aspectos temáticos de ambos conjuntos (Porcar 1945-75).

Después de los trabajos de J. Porcar, la Cova Remigia ha sido reseñada en diversas publicaciones como en el «Arte Rupestre Levantino» (Beltrán 1968); «Los tocados de plumas en el Arte Rupestre Levantino» (Jordá 1970-71), en donde se plantea el origen oriental de estos adornos. Este mismo autor utiliza iconografía del conjunto en sus artículos sobre «Formas de vida económica en el Arte Rupestre Levantino» y «La sociedad en el Arte Rupestre Levantino» (Jordá 1974), aportando formas de vida protohistóricas, con prácticas de una agricultura primitiva. Poco después publica «Las puntas de flecha en el Arte Levantino", observando la presencia de cuatro tipos de flechas (Jordá 1975).

Otro autor F. Esteve Gálvez analizaría algunas de las representaciones del Maestrazgo «Probable significado de unas pinturas rupestres del Maestrazgo» indicando la posible utilización de bolsas para contener veneno para las flechas ( $\mathrm{F}$. Esteve Gálvez 1975).

En 1978, coincidiendo con una campaña de estudio que $R$. Viñas estaba realizando en la zona, elaboramos un trabajo sobre «Las representacioines faunísticas del término de Ares del Maestre», contabilizando el total de representaciones de cada especie, así como su posición y actitud en cada escena. Este análisis puso de manifiesto una clara diferencia temática en los dos conjuntos de Cova Remigia y El Cingle de la Mola Remigia, observándose una clara representación de caza en el primero, mientras que en el segundo se observa una temática más variada. (Viñas y Sarriá 1978).

Un año más tarde y en colaboración con $F$. Monzonís y $\mathrm{R}$. Viñas preparamos otro artículo «Nuevas manifestaciones de arte rupestre en el Maestrazgo (Castellón)» (Monzonís, Viñas y Sarriá 1979).

Posteriormente M. Mesado Oliver, expone en su artículo «La Cova del Mas d'en Llorenç y el Arte prehistórico del Barranco de la Gasulla», la posible relación existente entre las cerámicas neolíticas de la Cova del Mas d'en Llorenç o Fosca y algunas representaciones de Cova Remigia y en El Cingle (Mesado 1981).

En los últimos años C. Olaria y F. Gusi han relacionado en distintos artículos abrigos pintados con el entorno arqueológico, publicando un «Avance preliminar del yacimiento Neolítico Antiguo de Cova Fosca (Castellón)» (Olaria y Gusi 1981); «Es- 
tudio del territorio para la comprensión del hábitat prehistórico. Un ejemplo del Neolítico Antiguo» (Olaria y Gusi 1984).

Recientemente cabe señalar la monografía que sobre la Cova Fosca «Un asentamiento mesoneolítico de cazadores y pastores en la serranía en el Alto Maestrazgo» ha publicado C. Olaria. En este estudio la autora se remite de nuevo a la probable relación de los abrigos pintados y su entorno arqueológico, aunque en su opinión «...sólo queremos remarcar la evidencia de la utilizaciión de estos abrigos pintados por los grupos que vivieron u ocuparon Cova Fosca» (Olaria 1988:379).

Por último cabe mencionar el interés por parte de organismos como el Institut Ghety Conservation que durante su curso sobre conservación de arte rupestre celebrado en Castellón, visitó el conjunto de Cova Remigia, para conocer su estado (Ghety C. 1987), así como la BBC de Londres, que utilizó las escenas de esta cueva, para documentar una serie televisiva sobre el antiguo hábitat en el Mediterráneo (BBC Londres 1987).

\section{SITUACIÓN Y DESCRIPCIÓN DE LA COVA REMIGIA}

La Cova Remigia, se halla situada en el término municipal de Ares del Maestre (1.194 m. s.n.m.) en la comarca del Alt Maestrat, provincia de Castellón. Esta cavidad se abre en la parte alta del barranco de Gasulla y en la base de los escarpes de la Mola Remigia.

Sus coordenadas son 30TYK443785, de la hoja n. ${ }^{\circ}$ 30-22 (570) del Servicio Geográfico del Ejército. Orientada al S.E. y a una altura de unos 920 m. s.n.m. (Fig. 1).

La Cova Remigia es un gran abrigo de unos 20 $\mathrm{m}$. de longitud, 9 de profundidad y 7 de altura. Está integrado por 6 concavidades que fueron denominadas por J. Porcar, H. Obermaier y H. Breuil, como cavidad I, II, III, IV, V y Pared Derecha, nomenclatura que hemos conservado a excepción de la Pared Derecha que describiremos como cavidad VI (Fig. 2).

Las cavidades varían entre los 2 y los $5 \mathrm{~m}$. de ancho; 1,5 y $9 \mathrm{~m}$. de profundidad y una altura que oscila entre 1,5 y $7 \mathrm{~m}$. de altura. Ninguna de estas oquedades presenta sedimento y las paredes están formadas por una superficie muy irregular, quebrada y formada por pequeños bloques.

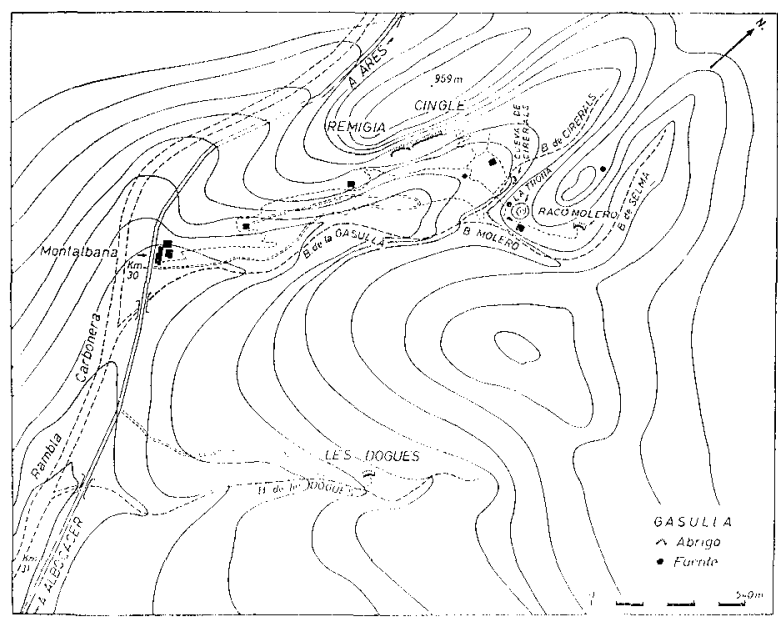

Fig. 1.- Situación de la Cova Remigia y otros conjuntos rupestres (según E. Ripoll).

Todo este conjunto así como los vecinos abrigos del Cingle de la Mola Remigia, son propiedad de la Diputación de Castellón y se hallan cerrados, por un muro, para la protección física de las pinturas. Es por lo tanto necesario en caso de visita, ir acompañado del guía que reside en el caserío de la Montalbana. Estos dos conjuntos rupestres se localizan a pocos metros de distancia y en el mismo farallón rocoso, convirtiéndose en el núcleo más rico y complejo, de este género pictográfico, no tan sólo de la provincia de Castellón sino de nuestra área mediterránea.

Para su localización es aconsejable partir de la carretera de Albocàsser a Vilafranca del Cid y desviarse en el km. 16 por una pista que remonta, desde el mismo caserío de la Montalbana, por la vertiente derecha del barranco de Gasulla (afluente de la Rambla Carbonera, la cual confluye con el nombre de Rambla de la Viuda al río Mijares). Después

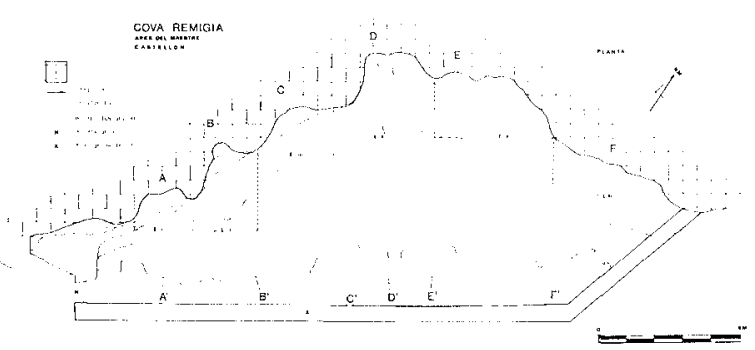

Fig. 2.- Topografía de la Cova Remigia. 


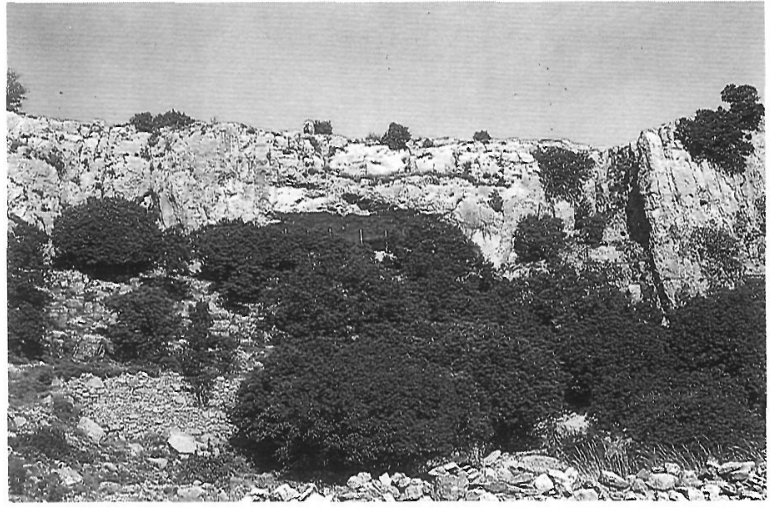

1. Vista general del conjunto rupestre de Cova Remigia.

de $2 \mathrm{~km}$. la pista finaliza y hay que seguir por el pie del escarpe unos $500 \mathrm{~m}$. hasta llegar a alcanzar la cavidad.

Cabe observar la presencia de otros conjuntos de pinturas rupestres, situados en los barrancos limítrofes, como el dels Cirerals, Racó Molero, Racó Gasparo, Les Dogues y el Mas del Cingle, los cuales a través de la Cova Centelles en el término de Albocàsser conectan con el conjunto de La Valltorta. También hay que reseñar por su interés arqueológico, los yacimientos tanto en abrigos como en cuevas, entre los que destaca la Cova del Mas d'en Llorens o Cova Fosca a unos $300 \mathrm{~m}$., al norte del conjunto que tratamos, convirtiendo todo este enclave en una de las zonas más interesantes para el

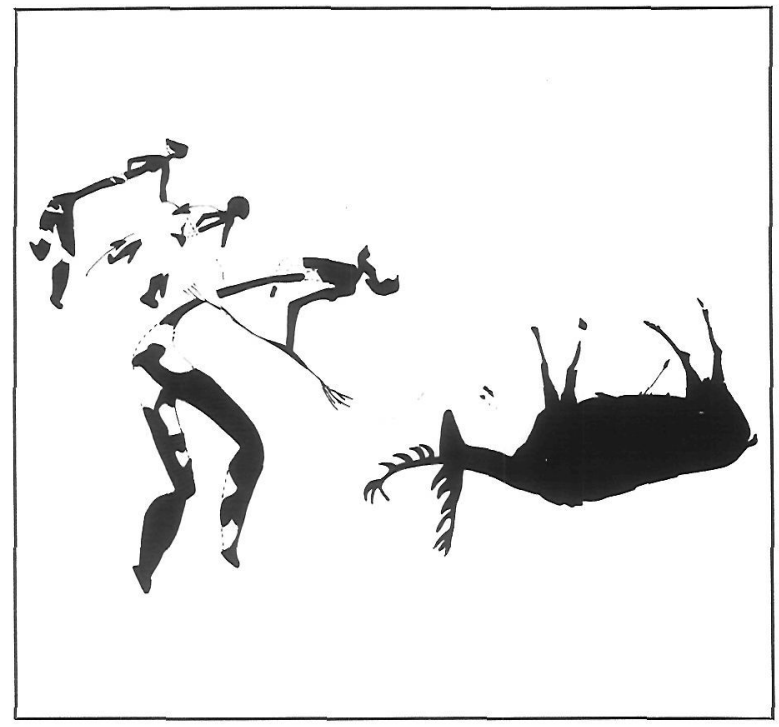

Fig. 3.- Escena de caza de ciervo. Cavidad V.

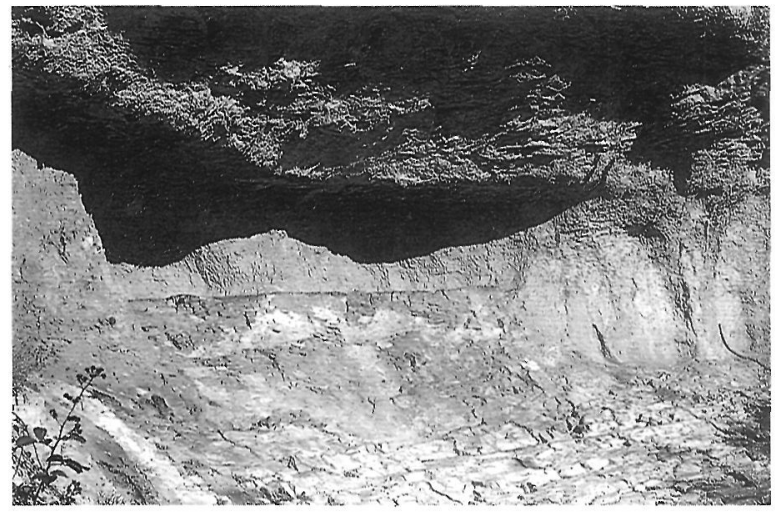

2. Vista general de la cavidad IV, V y VI (Pared Derecha).

estudio del arte rupestre «naturalista estilizado» postpaleolítico.

\section{TEMÁTICA}

A partir de las distintas asociaciones, existentes entre las figuras, hemos podido establecer 23 temas de los cuales 9 corresponden a composiciones relacionadas con la caza, y que representan el $58 \%$ de la temática de esta cueva. Entre estos temas predomina la caza de cápridos, seguida de los suidos y en menor cantidad, bóvidos y ciervos. Señalemos que a pesar de que los ciervos y toros están menos representados, dentro de las escenas de caza, por lo contrario representan algunos de ellos, los ejemplares de mayor tamaño y concretamente el ciervo que ocupa la parte central o más profunda de la cavidad, confiriéndole un lugar preferente y central, sobre las anteriores escenas de caza. (Fig. 3).

Dentro de las escenas de caza, también hay que incluir, las huellas, rastros y pistas, repartidas entre improntas humanas y de animales; las humanas son de mayor tamaño, mientras que las de los animales, muestran la pezuña bisulca y de pequeño tamaño. También encontramos en este grupo de representaciones formas alargadas y circulares que podrían corresponder a manchas de sangre dejadas por los animales o bien otros tipos de señales (Fig. 7).

El resto de la temática queda repartida entre animales y figuras humanas, un $25 \%$. Las figuras humanas aparecen con arco y sin arco y muchos de ellos podrían incluirse en los temas de caza, por la falta de flechas en los animales y la difícil relación de éstas con las humanas, deja a este núcleo sepa- 


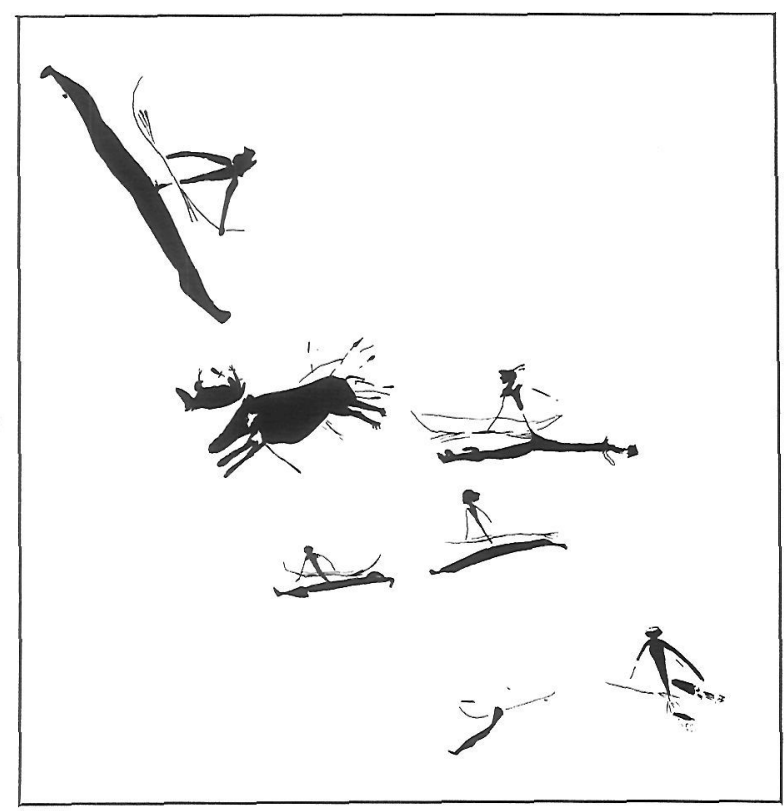

Fig. 4.- Escena de caza de jabalíes. Cavidad V.

rado de la temática estrictamente cazadora. Por último, queda un $18 \%$ que aparece dividido, de forma muy diversa entre: una escena de recolección; siete composiciones con cestos y objetos; tres paneles o colmenas; dos escenas de apariencia cotidiana; un grupo de hombres, tal vez guerreros; una escena de danza ritual, o ceremonia de carácter mítico; cinco personajes ejecutados, tres con pelotón y $2 \mathrm{sin}$; cuatro grupos de guerreros o pelotones de ejecución; tres posibles mujeres; una escena de acoplamiento; tres composiciones faunísticas y cinco escenas indeterminadas (Fig. 9, 10 y 11).

Entre la temática no cazadora, destaquemos las escenas de ejecución y personajes flechados o sacrificados que ya hemos mencionado y de los cuales existen cinco ejemplos, discerniendo entre escenas con y sin pelotón. Las figuras flechadas, sin pelotón pertenecen a las figuras estilizadas más naturalistas, mientras que las figuras flechadas con pelotón, son de pequeño tamaño y ofrecen características esquemáticas o semi-esquemáticas. Cabe observar que en el vecino conjunto del Cingle de la Mola Remigia, faltan por completo este tipo de escenas, y la temática cazadora ocupa un segundo plano de su temática (Viñas y Sarriá 1978), este hecho nos hace suponer que estas escenas de sacrificio, tan escasas dentro de este estilo, deben estar de algún modo relacionadas con normas jurídicas sobre el te-

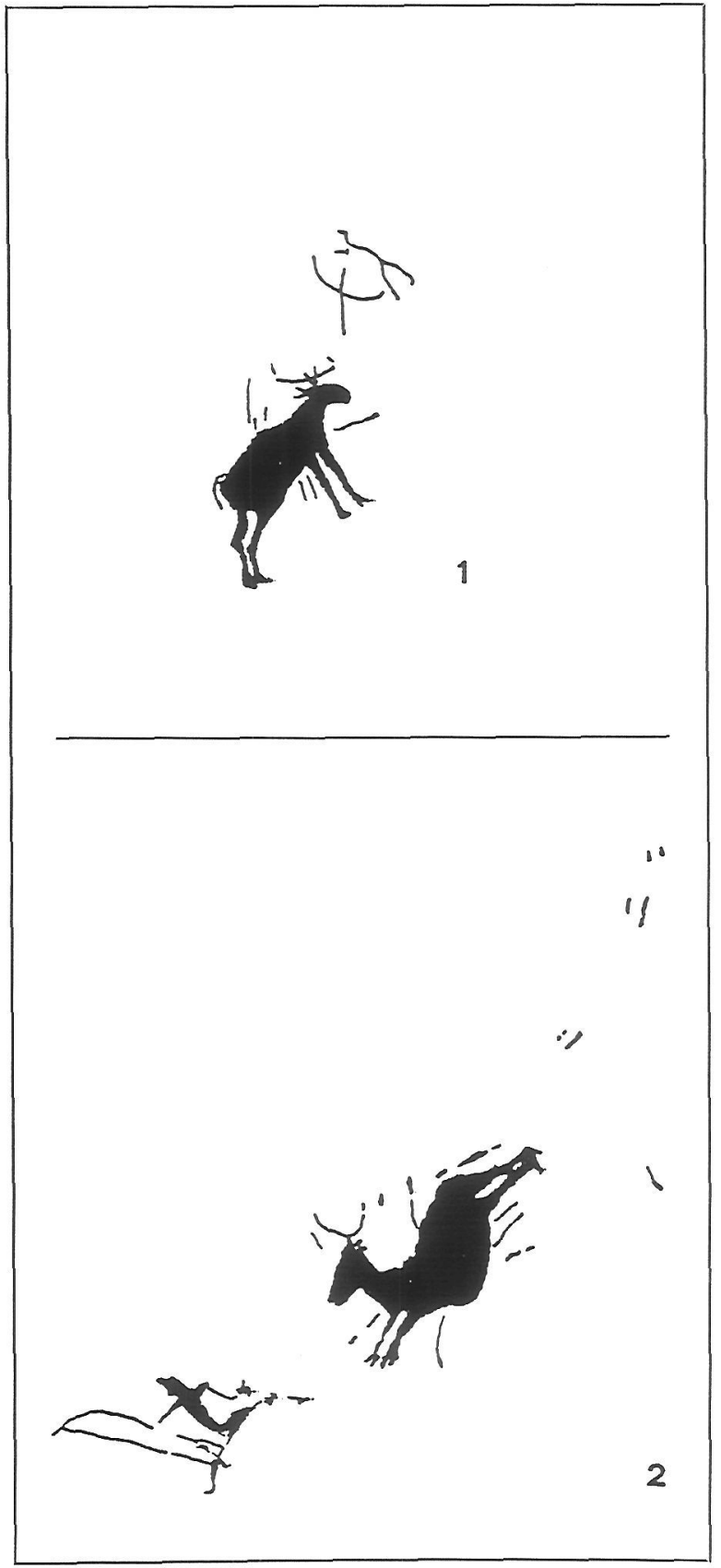

Fig. 5. - Escena de caza de toros o bóvidos. 1 y 2 cavidad II.

rritorio de la caza. En opinión de Viñas y Rubio se trata de ejecuciones simbólicas que «podrían corresponder a dos tipos de sacrificios: muertes por aplicación de reglas jurídicas o políticas; o bien muertes por ritual estrictamente religioso». (Viñas y $\mathrm{Ru}$ bio, en prensa) (Fig. 11). 


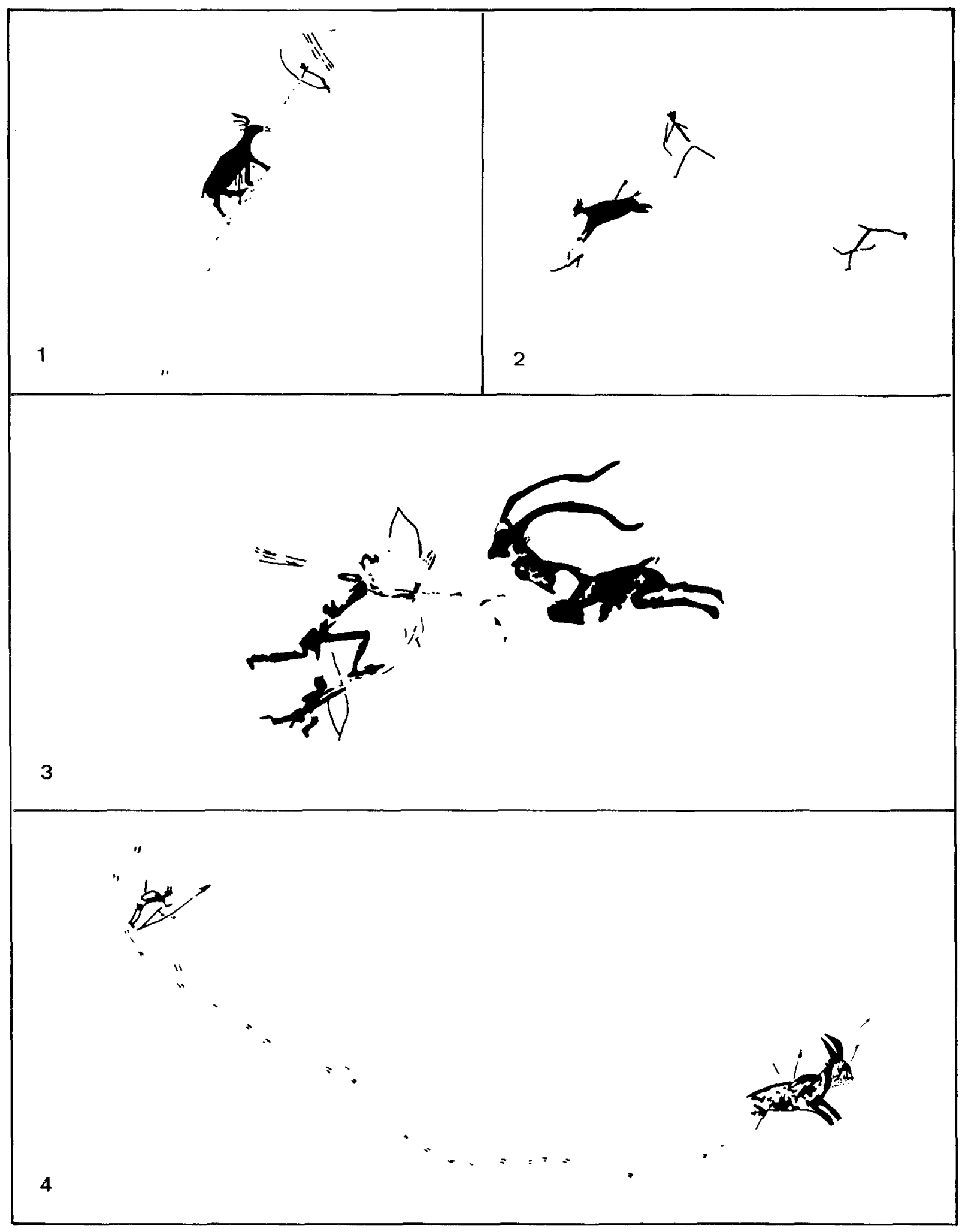

Fig. 6.- Escena de caza de cápridos. 1. Cavidad II; 2. Cavidad III;3-4. Cavidad IV.

13 


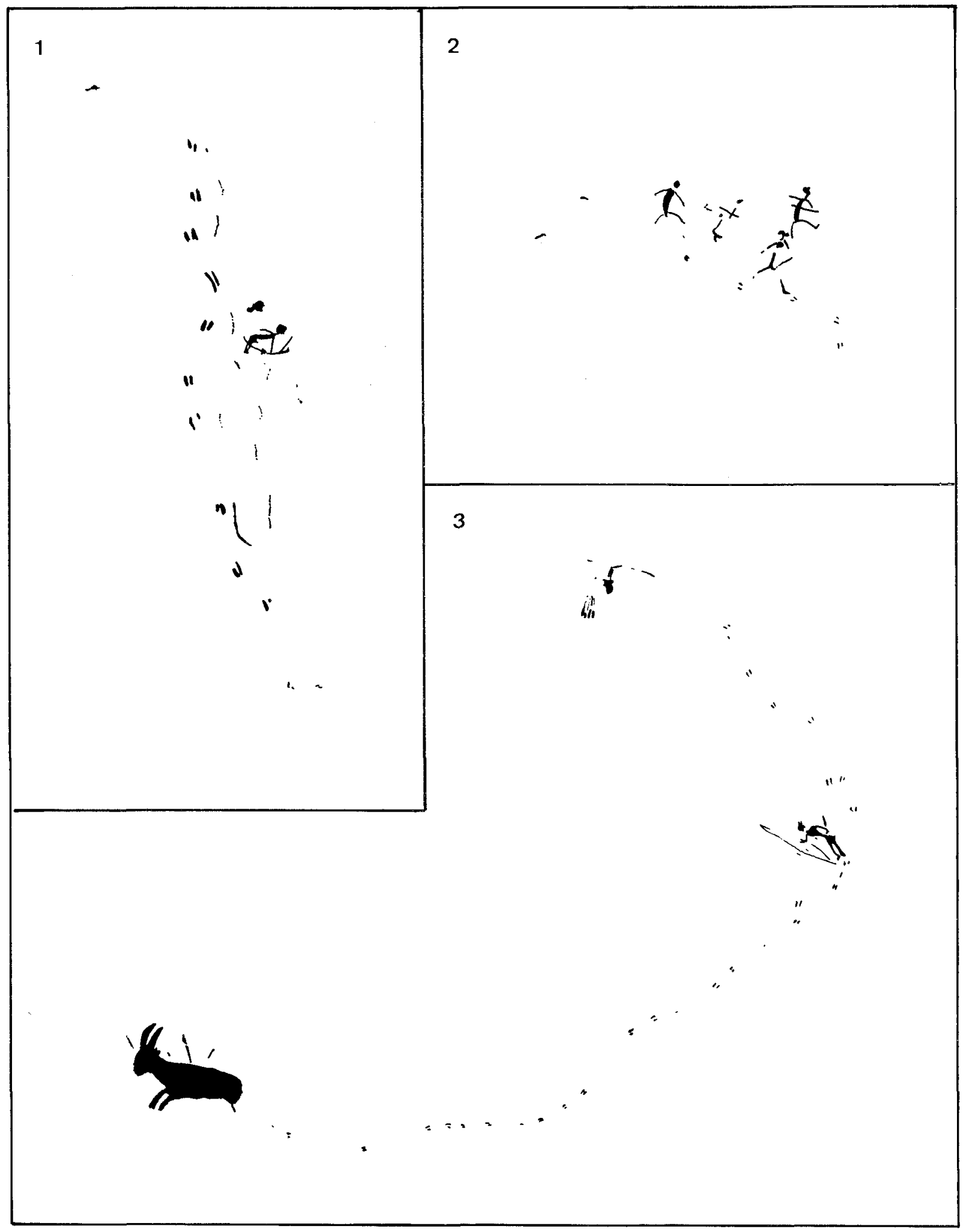

Fig. 7.- Escena de ojeo o rastreo. 1. Cavidad II; 2. Cavidad V; 3. Cavidad IV. 


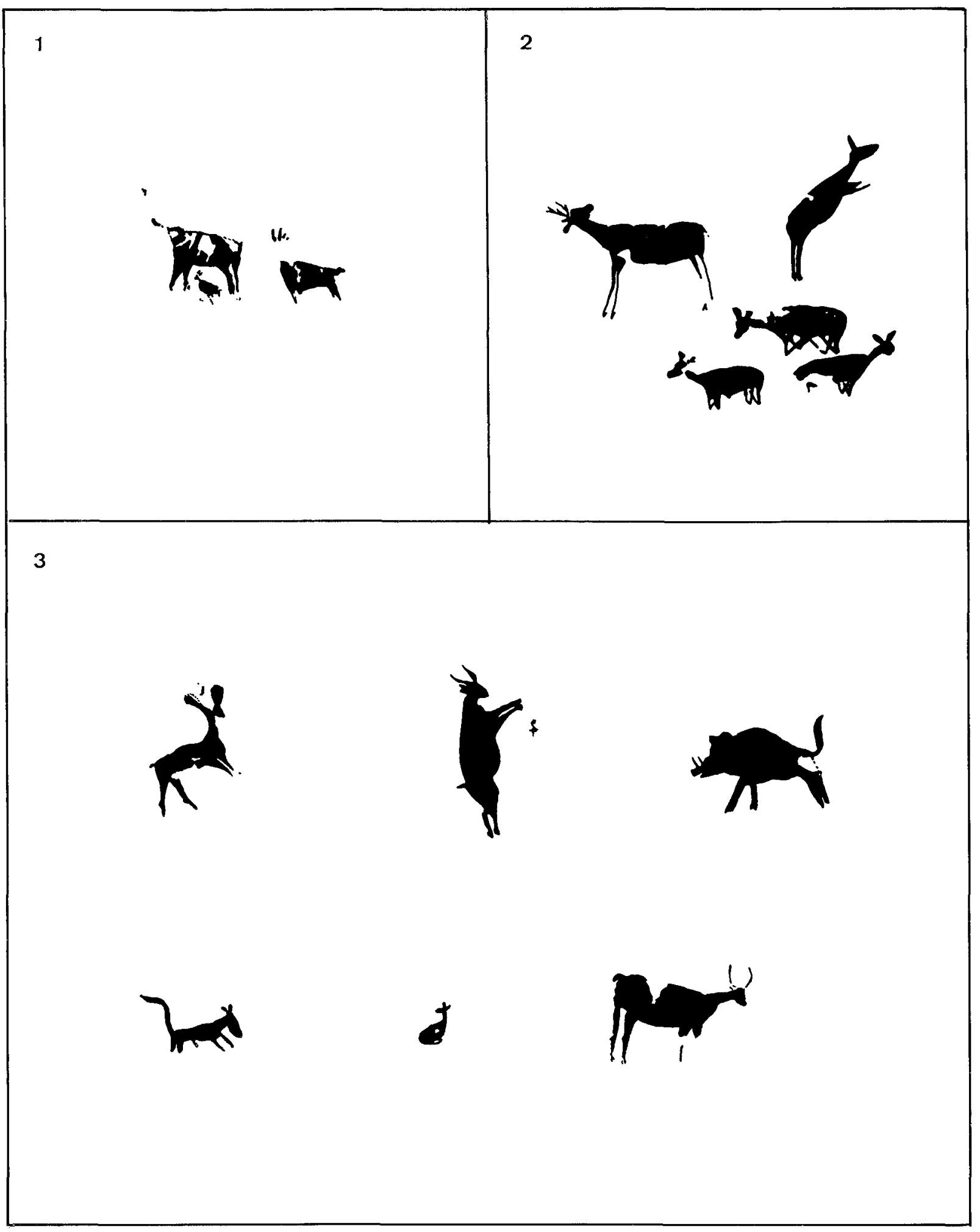

Fig. 8.- Escena de animales aislados y composición faunística de Cova Remigia. 1-2. Composición faunística; 3. Animales aislados. 


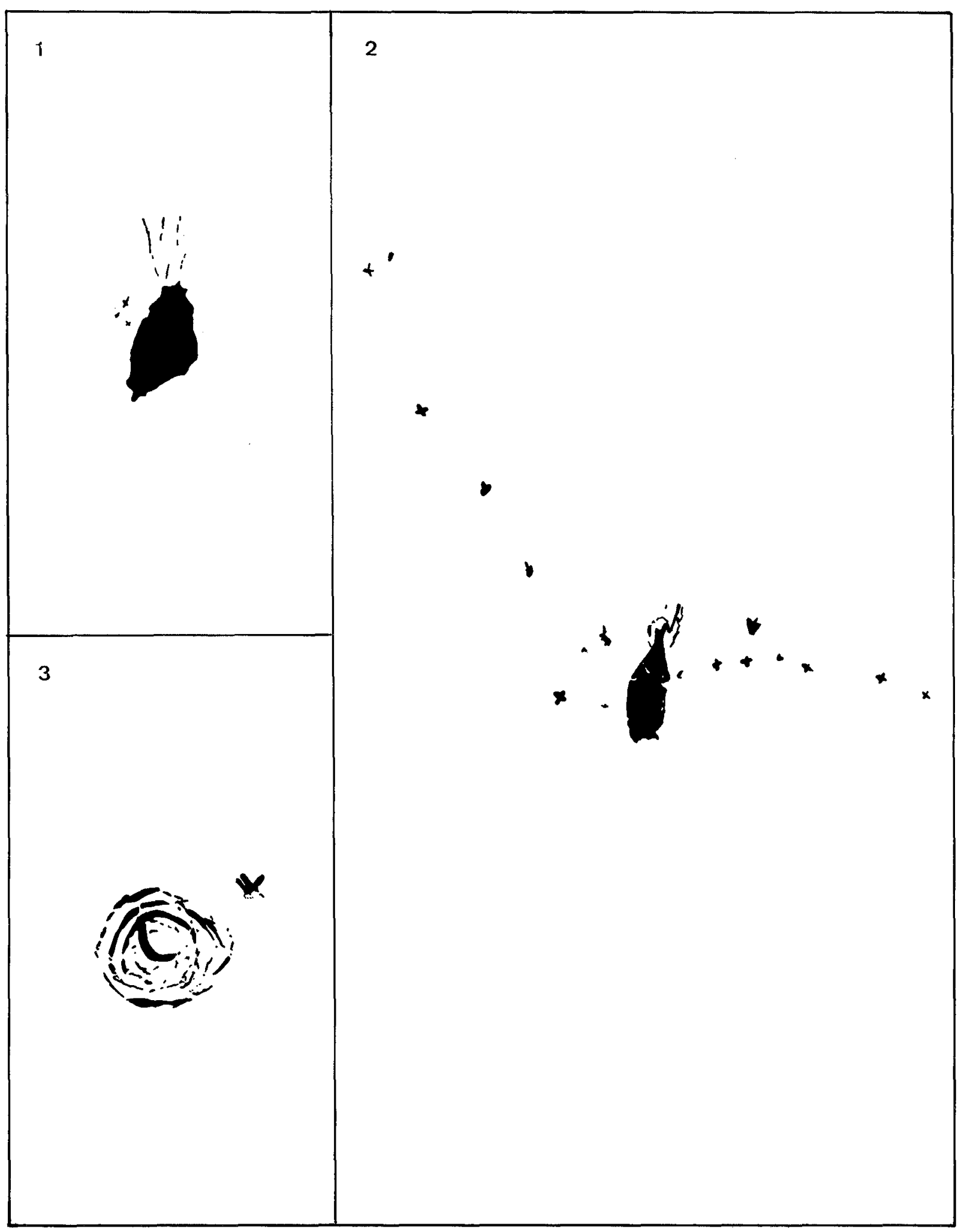

Fig. 9.- Representaciones de nidos o colmenas junto a insectos. 1-2. Cavidad IV; 3. Cavidad V. 


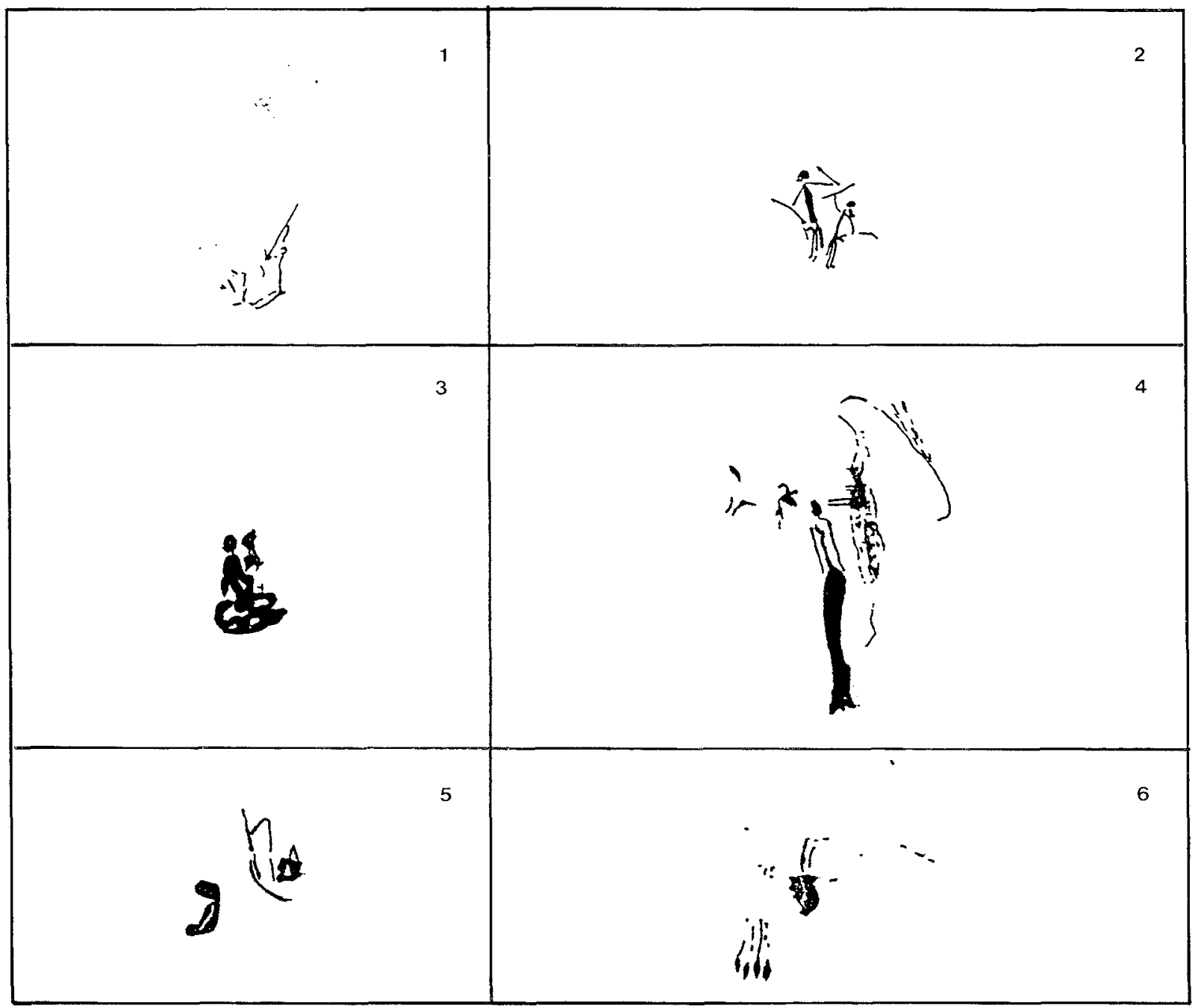

Fig. 10.- Cuadro con diferentes representaciones escénicas de Cova Remigia: 1. Recolección (cavidad III); 2. Danza (cavidałt IV); 3. Acoplamiento (cavidad V); 4. Mujer (?) (cavidad V); 5-6. Cestos y otros objetos (cavidad II y IV).

Un tema relevante, principalmente por su escasez es el representado por una pareja, al parecer ataviados con colas de animal (?), similares en cierta forma con otra pareja existente en el Cingle de la Mola Remigia (Fig. 10, n. ${ }^{\circ}$ 2, cavidad IV, n. ${ }^{\circ} 59$ y 60) (Viñas y Sarriá 1978). Estas dos figuras podrían estar representando una danza ritual o «ceremonia». Relativamente cerca de éstas, en la cavidad V, encontramos otra pareja de figuras humanas que por su posición creemos que podrían estar escenificando un acoplamiento (Fig. $10 \mathrm{n} .^{\circ} 3$, cavidad V, n. ${ }^{\circ} 139$ y 140 ). Este tema es prácticamente desconocido de la pintura "naturalista-estilizada» de nuestra área mediterránea.
Entre las 759 figuras que comprenden este conjunto, solamente un motivo ofrece ciertas dudas en cuanto a su clasificación dentro del estilo «naturalista-estilizado», pues tipológicamente bien podría incluirse en el ámbito de las representaciones «esquemático-abstractas». Se trata de la figura n. ${ }^{\circ} 87$, de la cavidad $\mathrm{V}$, formada por una serie de círculos concéntricos similares a los tipos de «petroglifos o espirales», de la denominada pintura esquemática. Pero la proximidad de un pequeño motivo, tal vez un insecto o un ave, nos hace pensar que podría tratarse, con todas las reservas, de un posible nido o colmena. Sobre este motivo J. Porcar comunicó que «En la part més alta hi ha un sig- 


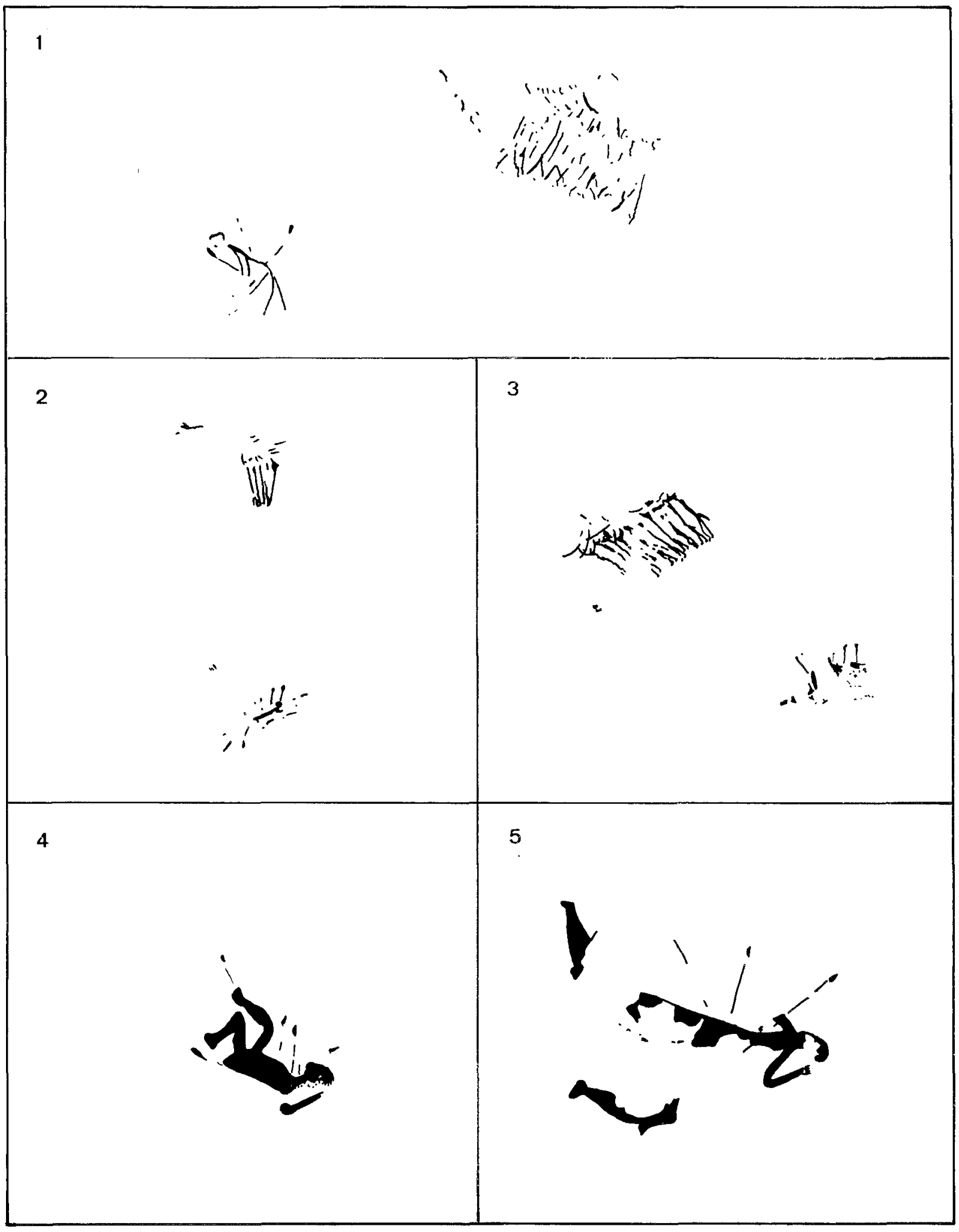

Fig. 11.- Escena de Ejecución o «sacrificio». 1-4. Cavidad III; 2-3. Cavidad V; 5. Cavidad I. 
ne de corbes concentriques en espiral (una serp?) que te un roig viu i sembla pertanyar a l'esquemàtic») (Porcar 1934). Más tarde en su monografía sobre Cova Remigia y en colaboración con $\mathrm{H}$. Obermaier y H. Breuil, se describió como «Conjunto con curvas concéntricas de color rojo claro. Para interpretar este dibujo, de cinco centímetros de diámetro, se tropieza con grandes dificultades. Se puede pensar en el esquema de una trampa para animales, de un panel o de una tela de araña...» (Porcar, Obermaier y Breuil 1935). De ser erróneas todas estas observaciones, sería el único ejemplo de un motivo «esquemático-abstracto» de todo el conjunto rupestre (Fig. 9, n. ${ }^{\circ}$ 3).

De los datos de la temática se desprende que el mural de la Cova Remigia, está representado por escenas basadas principalmente en la caza y por lo tanto un «santuario» dedicado a este tema o actividad económica. Estas características temáticas, lo separan del vecino conjunto de la Mola Remigia, El Cingle, que con la presencia de toros de gran tamaño y una reducción de las escenas de caza, se sitúa en un «santuario» dedicado a otros temas. Es-

CUADRO DE LAS REPRESENTACIONES ESCÉNICAS DE COVA REMIGIA

\begin{tabular}{|c|c|c|c|c|c|c|c|c|c|}
\hline & ESCENAS & c-1 & C.II & C-IIII & C-Iv & c-v & c.vi & rotal & $\%$ \\
\hline 1 & Caza de ciervo/s & & & 1 & & 1 & & 2 & 0,9 \\
\hline 5 & Caza de cabras & & 1 & 2 & & & & 3 & 1,4 \\
\hline 6 & Caza de cápridos & & & & 1 & 2 & & 3 & 1,4 \\
\hline 10 & Caza de jabalies & & & 2 & & 3 & & 5 & 2,3 \\
\hline 11 & Caza de toro/s & & 1 & & & & 1 & 2 & 0,9 \\
\hline 14 & Caza de animales indeterminados & & & 2 & & 13 & & 15 & 7,1 \\
\hline 15 & Relación con escenas de caza & & 4 & 3 & 3 & 14 & 1 & 25 & 11,9 \\
\hline 16 & Rastreo, ojeo, etc. & & 1 & & 3 & 14 & & 18 & 8,6 \\
\hline 17 & Escena de recolección & & & 1 & & & & 1 & 0,5 \\
\hline 22 & Escenas relacionada con cestos y otros objetos & & 4 & & 3 & & & 7 & 3,3 \\
\hline 23 & $\begin{array}{l}\text { Composición de paneles, colmenas, nidos, } \\
\text { insectos o aves }\end{array}$ & & & & 2 & 1 & & 3 & 1,4 \\
\hline 24 & Escena de apariencia cotidiana & & & & & & 2 & 2 & 0,9 \\
\hline 27 & Figuras de hombres & & & & & 1 & & 1 & 0,5 \\
\hline 28 & Escena de danza & & & & 1 & & & 1 & 0,5 \\
\hline 30 & Escena de ejecución o «sacrificio» & 1 & & 2 & & 2 & & 5 & 2,3 \\
\hline 31 & Grupo de arqueros o guerreros & & & 1 & & 3 & & 4 & 1,9 \\
\hline 40 & Figura de hombre aislada con arco y $\sin$ arco & 1 & 4 & 4 & 5 & 8 & 1 & 23 & 10,9 \\
\hline 41 & Figura de mujer aislada (?) & & & & 1 & 1 & 1 & 3 & 1,4 \\
\hline 43 & Acoplamiento (?) & & & & & 1 & & 1 & 0,5 \\
\hline 44 & Otras composiciones & & & & & 5 & & 5 & 2,3 \\
\hline A & Composición/es de caza, animales heridos, etc. & & 4 & 10 & 4 & 28 & 2 & 48 & 23 \\
\hline E & Composición faunística & 1 & & & 1 & 1 & & 3 & 1,4 \\
\hline \multirow[t]{2}{*}{$\mathbf{F}$} & Animales aislados & & 3 & 8 & 6 & 12 & 1 & 30 & 14,3 \\
\hline & TOTAL & 3 & 22 & 36 & 30 & 111 & 8 & 210 & 100 \\
\hline
\end{tabular}

tas diferencias temáticas, entre los dos conjuntos más importantes de esta área, pone de relieve la distinta funcionalidad de cada uno de estos abrigos rupestres, posiblemente coetáneos en el tiempo.

\section{REPINTES Y SUPERPOSICIONES}

Tanto en las descripciones como en las fichas, hemos ido anotando una serie de observaciones sobre repintes y superposiciones que constituyen la base de nuestra estratigrafía cromática y las cuales nos ayudan a esclarecer, sólo en parte, el proceso evolutivo o cronología relativa a las distintas fases de este conjunto.

Las superposiciones, no simpre son claras y será preciso revisar con más tiempo y medios los distintos ejemplos que expondremos a continuación. En cuanto a los repintes son a menudo simples bocetos sobre los cuales se aplicó el diseño definitivo, aunque en otros casos los repintes parecen haber sido realizados en un momento posterior, pues no siguen la imagen primigenia e incluso se practicaron en otro color, siempre para aumentar o resaltar el tono de las figuras.

A continuación pasamos a relacionar, mediante dos cuadros las figuras con repintes y superposiciones:

RELACIÓN DE LAS FIGURAS CON REPINTES:

\begin{tabular}{|c|c|c|c|c|c|c|}
\hline Cavidad & Color & Inicial & ler. & Repinte & $2 .^{\circ}$ & Repinte \\
\hline \multicolumn{7}{|c|}{ CAVIDAD I } \\
\hline 4 & D & 173 & $\mathrm{~F}$ & 180 & & \\
\hline 6 & D & 173 & F & 180 & & \\
\hline \multicolumn{7}{|c|}{ CAVIDAD II } \\
\hline 45 & D & 173 & $\mathrm{~L}$ & 181 & & \\
\hline 46 & D & 173 & $\mathrm{~L}$ & 181 & & \\
\hline 59 & D & 173 & $\mathrm{~J}$ & 174 & & \\
\hline 60 & D & 173 & $\mathrm{~L}$ & 181 & & \\
\hline \multicolumn{7}{|c|}{ CAVIDAD III } \\
\hline 42 & G & 194 & $\mathrm{~L}$ & 498 & & \\
\hline \multicolumn{7}{|c|}{ CAVIDAD IV } \\
\hline 14 & $\mathrm{~F}$ & 180 & $\mathrm{P}$ & 424 & & \\
\hline 20 & D & 173 & P & 424 & & \\
\hline $59 / 60$ & J & 167 & G & 195 & & \\
\hline \multicolumn{7}{|c|}{ CAVIDAD V } \\
\hline 12 & D & 166 & $\mathrm{~L}$ & 498 & $\mathrm{p}$ & 426 \\
\hline 15 y 22 & J & 167 & L & 498 & $\mathrm{p}$ & 425 \\
\hline 58 & $\mathrm{~F}$ & 180 & $\mathrm{~L}$ & 498 & & \\
\hline 118 & J & 167 & $\mathrm{~F}$ & 180 & & \\
\hline $180 / 182$ & $\mathrm{~F}$ & 180 & $\mathrm{p}$ & 426 & & \\
\hline 354 & P & 425 & G & 187 & & \\
\hline $389 / 399$ & $\mathrm{D}$ & 173 & $\mathrm{p}$ & 426 & & \\
\hline \multicolumn{7}{|c|}{ CAVIDAD VI } \\
\hline 25 & J & 174 & $\mathrm{~L}$ & 498 & & \\
\hline 26 & D & 173 & $\mathrm{~L}$ & 498 & & \\
\hline $27 / 28$ & D & 173 & L & 498 & & \\
\hline
\end{tabular}




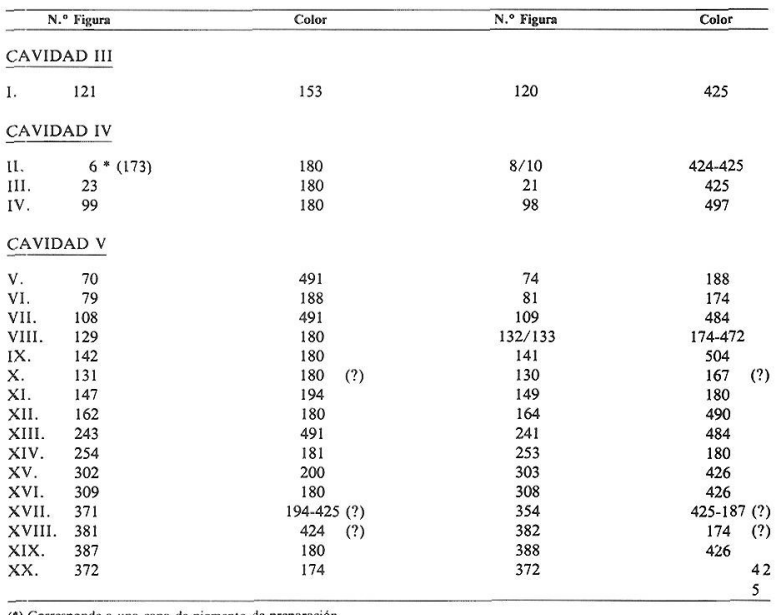

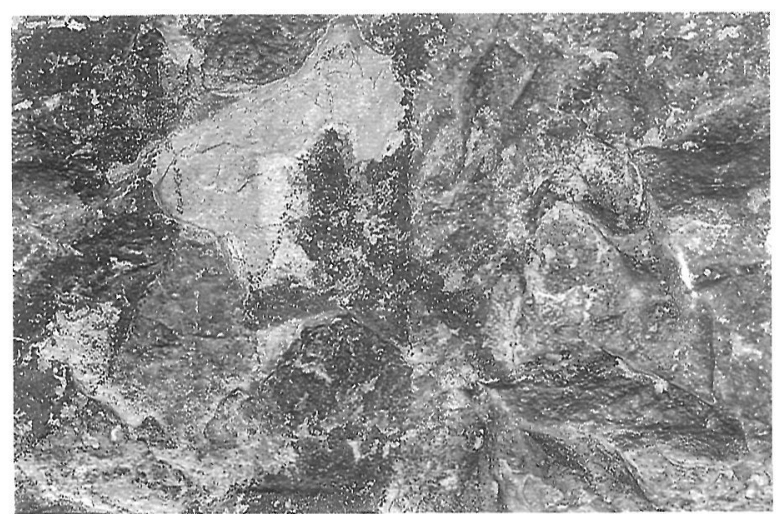

3. Detalle de la superposición de la figura del gran arquero correspondiente a la cavidad $\mathrm{V}$, la cual se superpone a la de otro arquero de tamaño más reducido.

De estas superposiciones se desprende la siguiente estratigrafía cromática:

ESQUEMA DE LAS SUPERPOSICIONES

\begin{tabular}{|c|c|c|c|c|c|c|c|c|c|c|c|c|c|c|c|c|c|c|c|}
\hline C-HII & (.). & & & & & & & & & C.V & & & & & & & & & \\
\hline
\end{tabular}

$\begin{array}{lllll}041 & 491 & 194 & 491 & 181\end{array}$

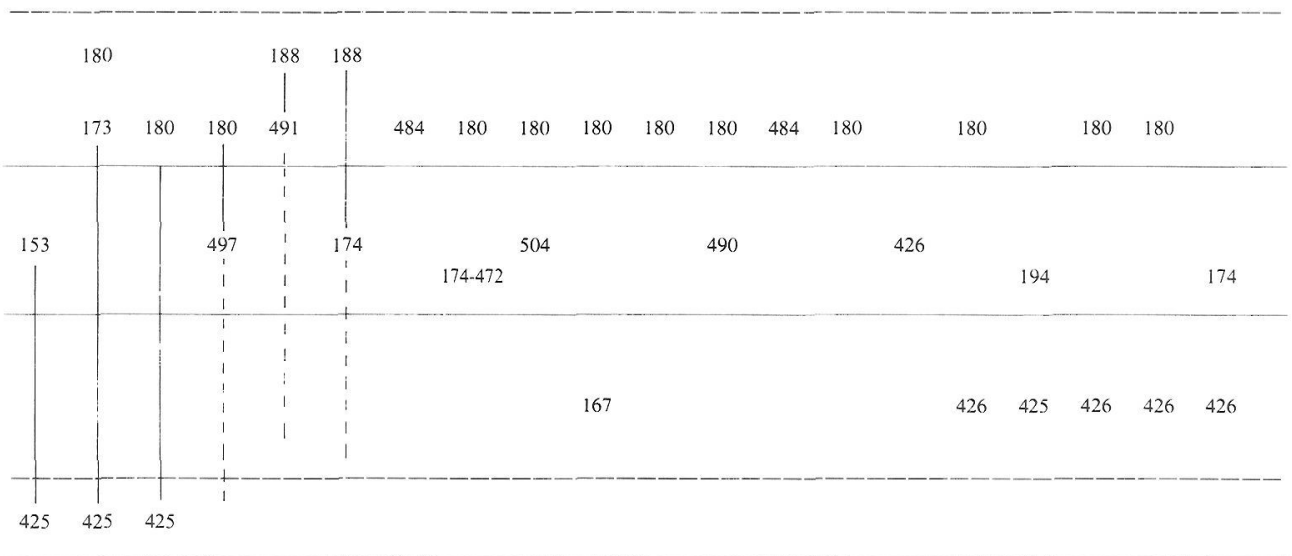

\section{PROCESO EVOLUTIVO DEL CONJUNTO}

Según los registros obtenidos en el color, repintes y superposiciones, se han podido obtener en Cova Remigia 7 momentos o fases de ejecución, que pasamos a describir.

\section{Fase I}

En el momento más antiguo del friso se distingue algunas figuras, la mayoría de ellas, en color negro, que corresponden por una parte a animales «proporcionados-naturalistas», entre los que figu- 


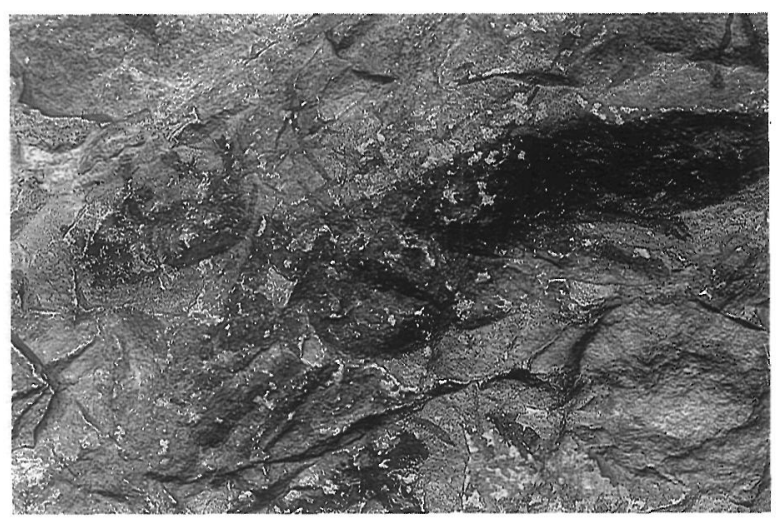

4. Figura de jabalí repintada en tres momentos. Un primero en castaño-rojizo (Pantone 167); segundo en castaño-rojizo oscuro (Pantone 498) y un último momento en negruzco (Pantone 425) (Cavidad V).

ran cápridos, en mayor número, y algún suido y cérvidos. Estos animales están emparentados con figuras de pequeño tamaño de trazo muy simple y la mayoría de ellas semi-esquemáticas, a excepción de una sola figura posiblemente femenina a la que han indicado el diseño de las caderas.

\section{Fase II}

La existencia de trazos en color rojo y preparaciones rojizas que cubren en parte las figuras de la primera fase, nos obliga a situar en un segundo momento o fase, figuras muy similares a las anteriores que aparecen a su vez bajo figuras naturalistas de mayor tamaño. Los animales presentan formas naturalistas que como veremos proseguirán durante todo el proceso pictográfico y que sólo es posible agrupar en este momento gracias a la presencia o relación con figuras humanas con las que forman escena. Las especies representadas muestran una cierta diversidad, diseñando cápridos, cérvidos y algunos bóvidos, entre los que cabe señalar la polémica figura supuesta como alce por $\mathrm{H}$. Breuil (3) y algún suido. Las figuras al igual que en la anterior fase son simples esquemas de trazos rectos sin ningún tipo de musculatura y solamente hacia la fase III se percibirá el modelado del relieve muscular. Todas estas figuras corresponden a la gama del rojocastaño. Cabe observar que ya desde la primera fase se percibe un gran movimiento tanto en las figuras humanas como en los animales.
Fase III

Esta fase la hemos subdividido en tres momentos (A-B-C), por la distinta anatomía de las figuras humanas. En un primer momento (III-A), incluimos una serie de figuras que por su situación aparecen infrapuestas a tipos de mayor tamaño y estilos distintos. La tipología de estas figuras corresponde a cuerpos de tronco recto y piernas gruesas y algunos animales que siguen la línea naturalista, observando en este momento la figura de un posible jabalí muerto con técnica de silueteado, en colores castaños y castaño claro.

En el momento (III-B), las figuras presentan un mayor realismo con cuerpos más proporcionados con la presencia de algún tipo de adorno: colgantes sobre las rodillas; colgante entre las piernas; posibles plumas dobladas sobre la cabeza y posibles protectores en piernas. Los animales también presentan al igual que las figuras humanas formas muy naturalistas y proporcionadas. Indiquemos que en este momento las figuras fueron realizadas en colores más densos castaños y rojos. Por el estilo también cabe incluir en este momento una pequeña figura humana y un cáprido con el que forma escena en color negro.

En el momento (III-C), las figuras se estilizan presentando troncos delgados con indicación del tórax y piernas con adornos o protectores muy similares a las anteriores figuras. En toda esta fase III, predominan las figuras en actitudes muy dinámicas, aunque cabe señalar que estas posiciones ya aparecen en los primeros momentos del mural. En cuanto a los animales parecen predominar los cápridos y los cérvidos aunque continúan apareciendo los bóvidos y los jabalíes. Cabe señalar que en esta fase aparecen representados el jabalí y el cáprido de mayor tamaño ocupando zonas distintas del mural concentrándose las escenas de suidos en una parte y cápridos en otras.

Los colores predominantes en esta fase son el rojo y el castaño, con algunas pocas figuras en negro. Observemos que entre ellas destacan tonos sumamente densos y oscuros.

\section{Fase IV}

Por el estilo de la fase III-C, debería corresponder las formas de la fase $\mathrm{V}$, que parecen representar el máximo exponente de la citada fase, pero la 


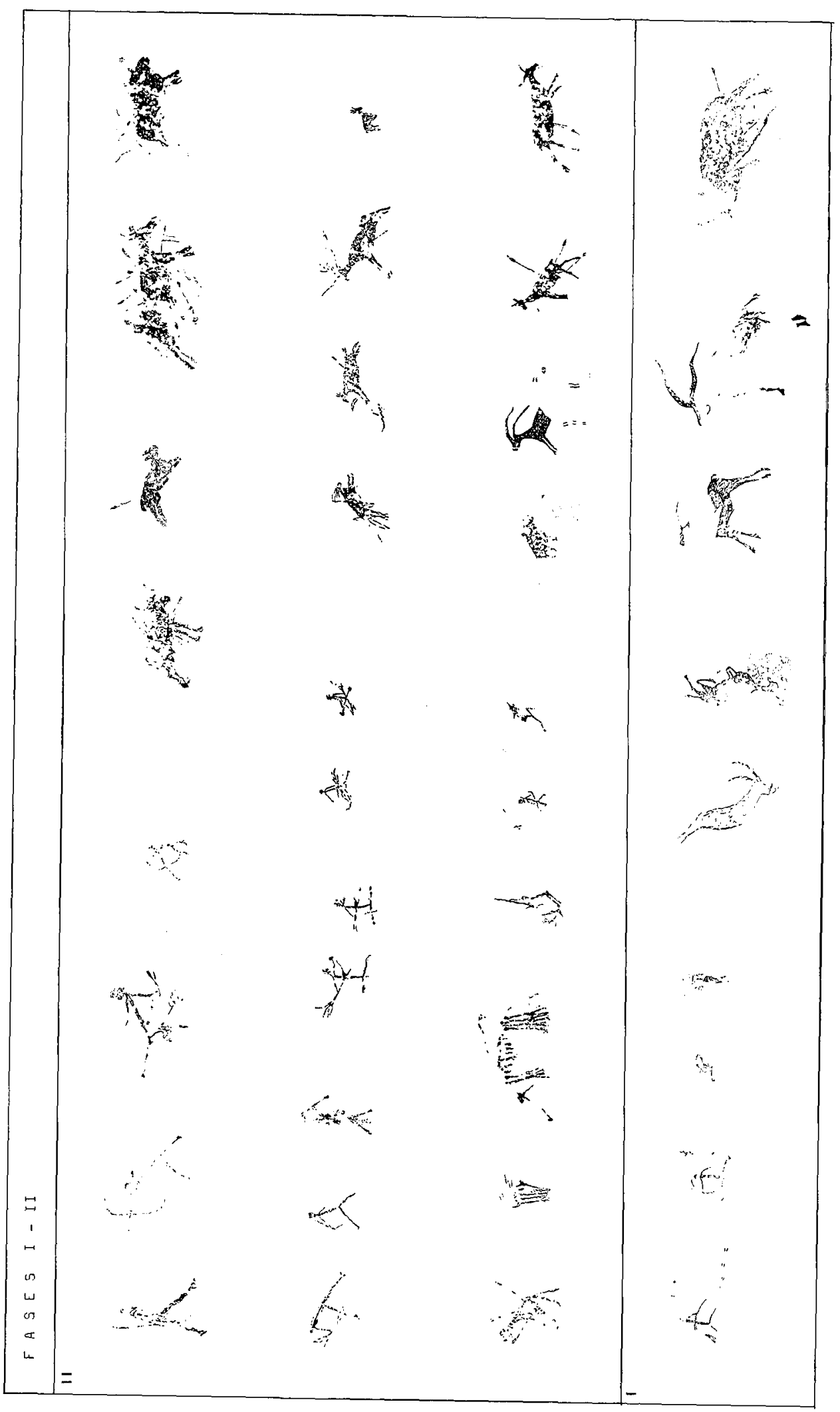




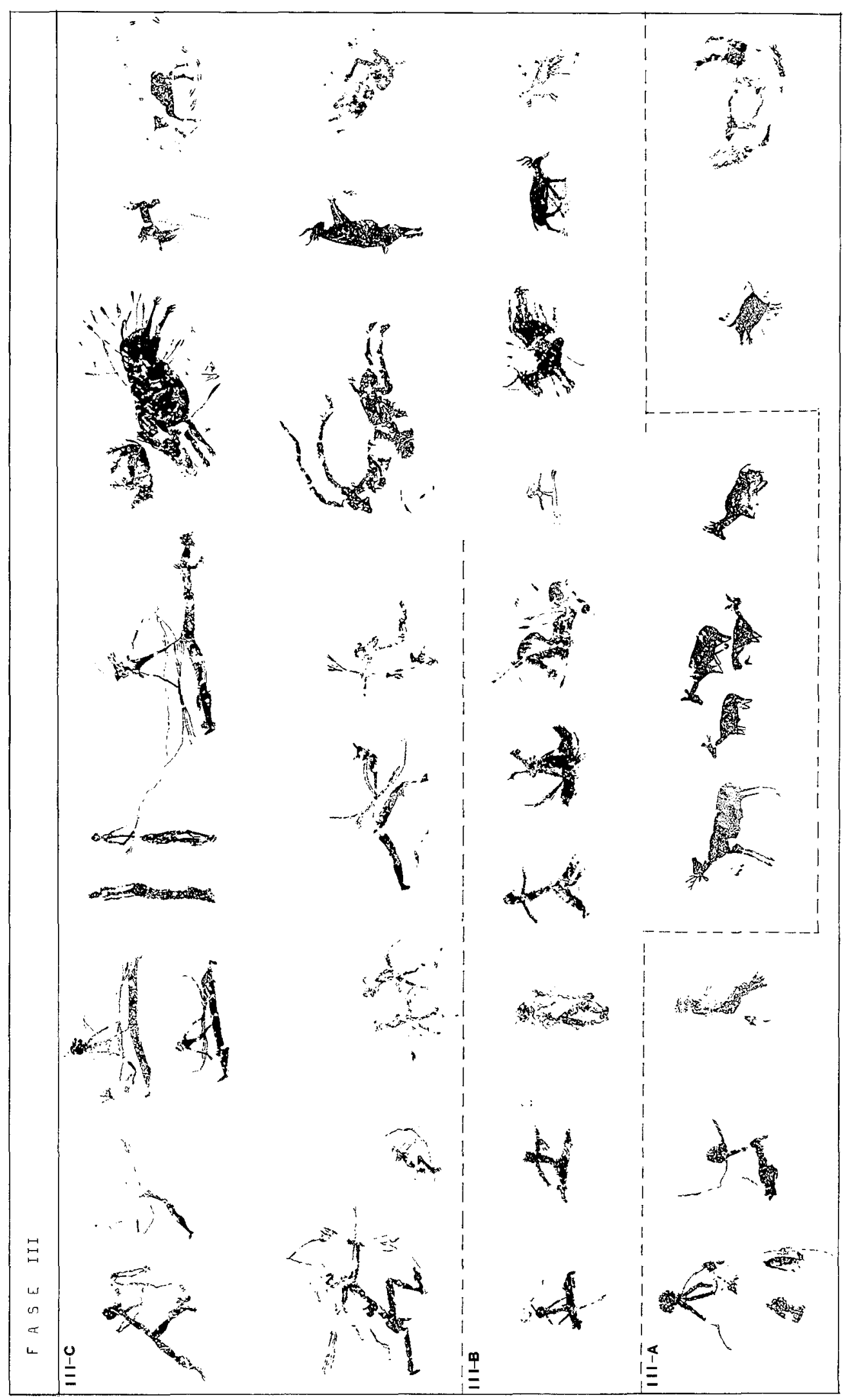




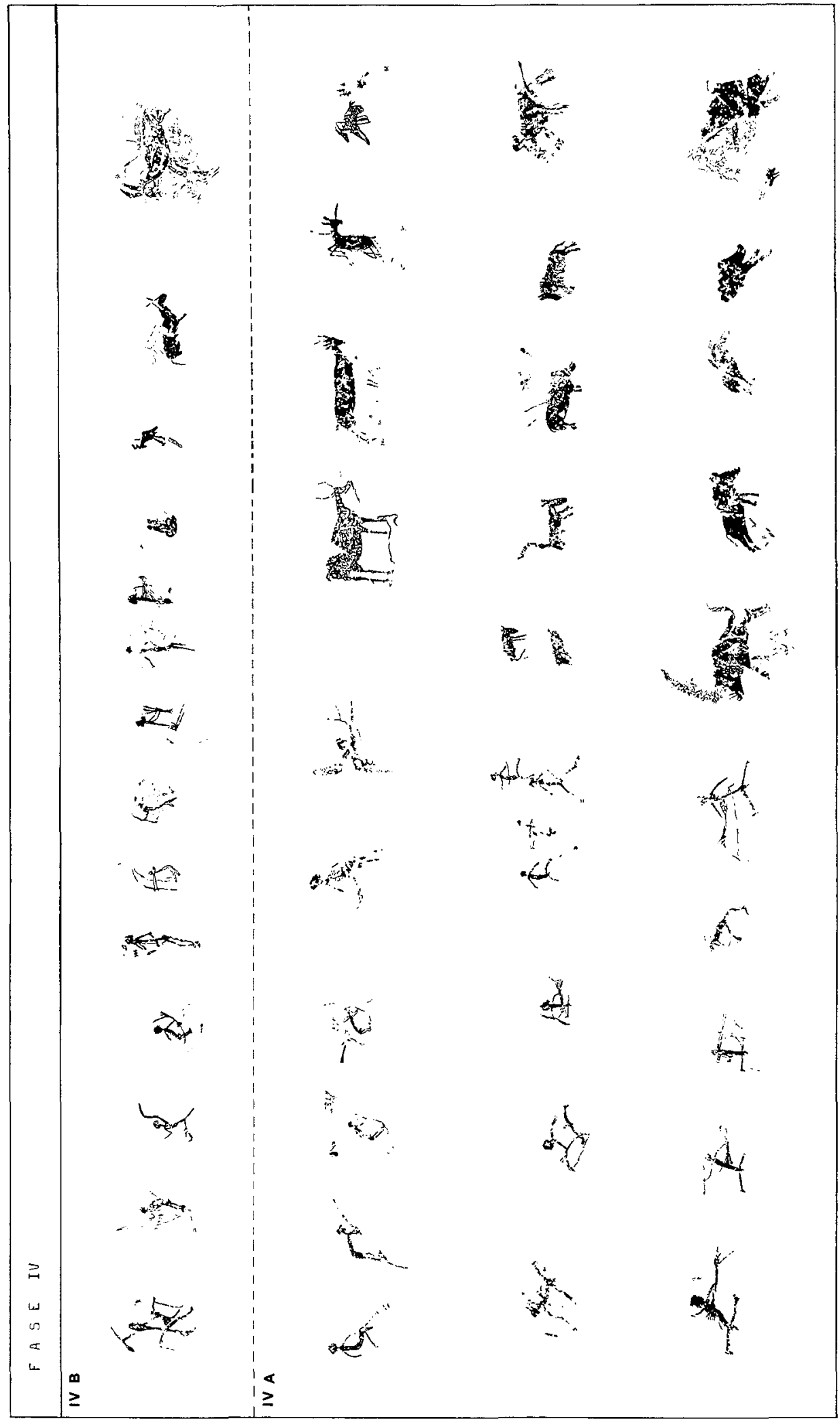




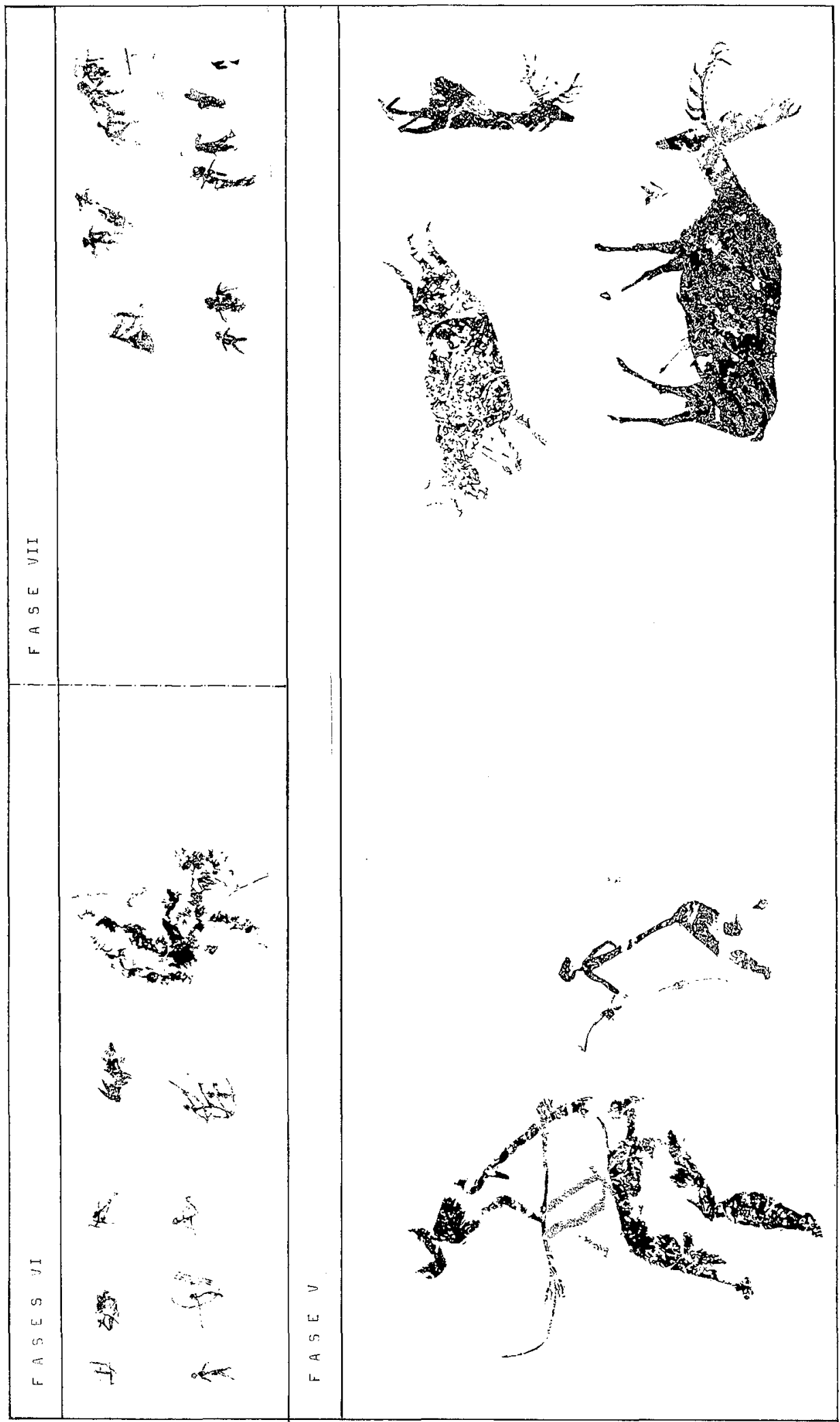


existencia de una figura de pequeño tamaño por debajo de la pierna del gran arquero n. ${ }^{\circ} 129$, así como otros detalles, como el jabalí $n .^{\circ} 74$, que aparece entre las piernas de la figura del gran arquero $n .^{\circ}$ 70 , apuntan hacia un nuevo momento de figuras humanas semi-esquemáticas.

Esta fase se puede subdividir en dos momentos A y B, debido a la distinta anatomía de las figuras humanas. En el primer momento estarían las representaciones humanas de tipo semi-esquemático con piernas rectas y delgadas, indicación de los pies, con el tronco recto más ancho, percibiéndose el diseño en una gran mayoría de ellas del falo, ya visible en alguna de las figuras de la fase III. En el segundo momento, las formas son muy diversas predominando troncos delgados con indicación algunos de ellos, del tórax.

En cuanto a los animales, a pesar de la existencia de cápridos predominan los jabalíes, algunos de ellos con el pelo erizado. También aquí se detecta la presencia de un carnívoro (cánido?). Anotemos que entre las representaciones faunísticas se detecta una cierta estilización produciendo formas longilíneas y cierta simplicidad en los detalles. Resaltemos que la fase IV-A, corresponde al momento con mayor número de ejemplares de jabalíes. Los colores utilizados son rojizos, castañosrojizos y negros.

\section{Fase V}

En este momento cabe situar las dos figuras humanas una de ellas de mayor tamaño, del conjunto y por su proximidad tanto estilística como escénica el gran cérvido aparentemente muerto $n .^{\circ} 123 \mathrm{y}$ el gran bóvido $\mathrm{n} .^{\circ} 26$ de la cavidad VI.

Las figuras humanas constituyen la máxima estilización del tronco conservando las piernas completamente naturalistas, tipo iniciado ya, en la fase III. Destaca su cabeza en forma elipsoidal que lo encuadra con otras representaciones de esta área del Maestrazgo y sur de Tarragona.

Los colores utilizados son los rojizos y castañorojizos.

\section{Fase VI}

Esta fase parece representar un último momento que vendría a suponer la pervivencia de formas precedentes, existentes ya en la fase IV, y que al parecer fueron añadidas, sumándose a antiguas escenas.

Las figuras humanas representan formas semiesquemáticas de pequeño tamaño, simples y austeras, en sus detalles que por la simplicidad de sus formas recuerdan a las figuras de las primeras fases. Los pocos animales de este momento son de mayor tamaño presentando formas de diseño simple.

Los colores utilizados corresponden a las gamas del rojo-castaño.

\section{Fase VII}

Aunque no tenemos ningún tipo de superposición que indique su situación estratigráfica, todo hace pensar por la ubicación que ocupan al final de la cavidad IV y entre el gran conjunto de caza de cápridos y suidos que se escogió una zona sin pinturas para representar una escena particular, de lo contrario creemos que las figuras se hallarían rodeadas de otras representaciones.

Las figuras humanas presentan diseños esquemáticos de trazos rectos y con cierto relieve, destacando una posible figura femenina con falda, sosteniendo un bastón o atributo y grupo de figuras que muestran unos adornos colgantes en la parte superior del brazo y que cuelgan hasta la cintura.

Los colores utilizados son los rojizos y castañorojizos.

\section{CONTEXTO ARQUEOLÓGICO}

En las proximidades de la Cova Remigia son conocidos desde antiguo diversos yacimientos arqueológicos pertenecientes a distintas épocas, señalemos como más cercano el situado a unos $100 \mathrm{~m}$. y en el mismo farallón, el denominado Mas de Modesto en donde Joan Porcar, señala «Petita zona d'estelles de sílex i enterrament d'on el masover Modesto ha extret les sagetes i destral que guarda en son poder» (Porcar 1934). Este lugar constituye un pequeño abrigo de escasa profundidad y cuya visera se desplomó sobre el yacimiento. En la actualidad todavía aparecen restos de talla por debajo de un bloque que sería de interés levantar y proceder a la excavación de la pequeña zona de unos $2 \mathrm{~m}$. por $1 \mathrm{~m}$. con una profundidad de unos $50 \mathrm{~cm}$. aproximadamente. En nuestras visitas hemos podido re- 
coger diversos restos de talla, laminitas, algunos núcleos, varios raspadores, laminitas de dorso rebajado, y pequeños restos óseos, que podrían enmarcarse posiblemente en un neolítico y bronce (4).

El mismo Porcar en el citado trabajo comenta también otros 4 lugares, como el del Mas del Cirerals o Cireres, Cova Gran, Roqueta de la Trona y Mas Nou (Porcar 1934). En distancia el segundo conjunto más cercano a la Cova Remigia sería la Cova del Mas dels Cirerals o Cirerers a unos $200 \mathrm{~m}$. y en el margen izquierdo del barranco dels Cirerals, es decir en frente de la Cova Remigia. En este yacimiento, Porcar señala «sagetes rojes... Aquesta cova es interessant perquè mira cara al Nort i conté un Ilit de jaciment amb mobiliari neolitic i fa pensar que les capes profundes estiguen baix, nivell de llit del barranc». (Porcar 1934). Este abrigo, de unos $20 \mathrm{~m}$. de largo, 3 de profundidad y unos 2 de altura, fue utilizado antiguamente como redil, y en el piso no existe actualmente sedimento alguno. Cabe la posibilidad de que el posible sedimento fuera eliminado de la cavidad y depositado en la ladera que cae sobre el pequeño barranco. Actualmente toda esta zona está cubierta de vegetación y no se observa en superficie ningún resto, por lo que sería de interés proceder a una excavación del lugar. Por encima de este yacimiento y en la cumbre del lugar denominado La Trona, Porcar señala «despoblat argàrico en planta» (Porcar 1934). En este lugar existen restos de estructuras y un pequeño túmulo que fue excavado según información, por González Prats, desconociendo los resultados del mismo. En la actualidad el poblado está arrasado por la erosión y se encuentran pequeños fragmentos muy rodados de cerámicas a mano.

Por detrás de La Trona y en el barranco Molero, en una zona de bosque al pie del cantil, Porcar señala el yacimiento del Mas Nou, diciendo «petita zona on pareix quantitat d'estelles de sílex acusant un taller a l'aire lliure» (Porcar 1934). Este lugar ha sido objeto de estudio por Francisco Gusi y Carmen Olaria los cuales han llevado a cabo una excavación del yacimiento cuyos resultados todavía no han sido publicados. Al parecer este yacimiento arqueológico fue descubierto al rebajar una parte del camino que conduce al Mas Nou, apareciendo pequeñas hojas de sílex y cerámicas, posiblemente incisa.

(4) Materiales pertenecientes al Neolítico y Bronce, según revisión realizada por el Dr. Josep M. ${ }^{a}$ Fullola i Pericot.
Joan Porcar, al citar la Cova Gran (Cova Fosca) señala «un llit inmens de jaciments del neolític i eneolític» (Porcar 1934).

En 1977, J. Aparicio Pérez y J. San Valero Aparici, publican un trabajo sobre «La Cova Fosca (Ares del Maestre, Castellón) y el Neolítico Valenciano» en la serie arqueológica que publica la Universidad de Valencia. En este trabajo se comenta, según los autores la «existencia de una segunda fase neolítica entre el Antiguo Neolítico con cerámica cardial...» (J. Aparicio y S. Valero 1977). Esta fase ya había sido observada por Fletcher en las estratigrafias de los yacimientos valencianos Or, en Pardo, fase que situaba durante el IV milenio y V como simple continuidad del Neolítico I Cardial (J. Aparicio y S. Valero 1977).

En 1981, M. Mesado publica un artículo sobre la «Cova del Mas d'en Llorens y el arte prehistórico del barranco de la Gasulla». En este artículo el autor describe una serie de materiales, que les fue entregado por Isidro Salvador del Mas Nou, el cual los había recogido de los bancales del «planell»y que procedían del yacimiento de la cueva utilizados como fertilizantes. Este autor describe estos materiales situándolos en el Neolítico (Mesado 1981). El autor más adelante establece la posible relación de la cova del Mas d'en Llorens con las pinturas de la Gasulla y señala que «En las pinturas del Barranc de la Gasulla, destacan Cova Remigia y el Abrigo del Cingle de la Mola Remigia, que con Racó de Molero, son a nuestro entender, manifestación directa del hábitat de la Cova del Mas d'en Llorens» (Mesado 1981). Más adelante $M$. Mesado señala que «ya que en la monografía de esta cueva (se refiere al estudio de Porcar, Obermaier y Breuil 1935) no se ha hecho relación a esta problemática (cronología del arte rupestre), volvemos sobre las fases estilísticas de Cova Remigia, pues los diversos estilos son allí bien claros» (Mesado 1981). Sobre esta cuestión trataremos más adelante.

Poco después, Carmen Olaria publica sus trabajos realizados en Cova Fosca estableciendo 3 fases de ocupación: Fosca I, II y III. Fosca I paralelizable con la industria lítica del complejo geométrico de Cocina (Cocina III) (5.260 - 70 BC.). Fosca II, representa un momento inicial de transición entre el viejo sustrato epipaleolítico final de Fosca III y las primeras manifestaciones de Fosca I, neolítico con una débil intrusión de piezas geométricas, tipo Cocina (Cocina III). Fosca III, parece representar una etapa posterior de la fase A, del comple- 
jo geométrico del Filador, es decir paralelizable con los niveles II y I superficial de Filador con ausencia de geométricos ( $7.510 \pm 160$ B.C.).

Todos estos datos comprenden el contexto arqueológico más próximo a Cova Remigia y con los cuales se deberá contar a la hora de establecer cualquier interpretación crono-cultural.

\section{PROBLEMÁTICA CRONO-CULTURAL}

Desde el descubrimiento, a principios de este siglo, del arte «naturalista-estilizado» al aire libre, el tema de su filiación crono-cultural no ha dejado de preocupar a los estudiosos de este campo. Hoy, a pesar de los avances registrados en la investigación arqueológica, el aspecto crono-cultural sigue sin resolverse al menos por lo que respecta a su origen, desarrollo y desaparición de cada una de las áreas geográficas en donde se ubica este tipo de manifestaciones.

Si repasamos el curso de las investigaciones sobre este arte rupestre, comprobaremos que los estudios se han ido basando en la propia temática, la fauna representada, la superposición de estilos y color, y por último el contexto arqueológico cercano a los abrigos pintados. De este modo encontramos a $\mathrm{H}$. Breuil y $\mathrm{H}$. Obermaier como principales defensores de una filiación crono-cultural paleolítica, aunque de forma paralela y ya desde su inicio también surgen los que proponen, por el contexto arqueológico, una cronología neo-eneolítica. Entre estos últimos tenemos a Durán i Sampere, Matías Pallarés, Bosch Gimpera y otros estudiosos que inician los trabajos arqueológicos en el conjunto de La Valltorta, señalando «...el material recullit en aquests camps oberts i el que pogué esser extret de les coves forma un conjunt d'alguns centenars d'objectes típics de la industria lítica neolítica i eneolítica...» (M. Pallarés 1920).

Obermaier que también trabajó con P. Wernert en el estudio de las pinturas de La Valltorta las consideró paleolíticas, mientras que el equipo de B. Gimpera las consideró neo-eneolíticas. Así desde el inicio de estas investigaciones tenemos presentes las dos teorías que de un modo u otro han ido rigiendo los estudios hasta nuestros días.

Años después, M. Almagro, recoge las ideas propuestas por H. Pacheco y Santa-Olalla sobre la cronología mesolítica y rechazando las especies fau- nísticas cuaternarias de tipo frío, propuso una filiación mesolítica para las pinturas (Almagro 1944). Este autor se basó en el contexto arqueológico de estos yacimientos rupestres, cronología que continuó defendiendo en la monografía dedicada al covacho de Cogul, lamentando además la postura de $\mathrm{H}$. Breuil, que desprestigió los trabajos de anteriores estudiosos que proponían para Cogul una cronología neolítica (Almagro 1952).

A la nueva idea mesolítica, se sumaron diversos autores, entre ellos E. Ripoll y A. Beltrán, que en la década de los años 60 establecen 4 fases para todo el proceso de este arte rupestre de la Península Ibérica (Ripoll 1964 y 1966, y Beltrán 1968). Para E. Ripoll este arte rupestre habría que situarlo, su inicio, hacia el $8000 / 7500$ a. C., es decir un origen mesolítico entroncado con el Perigordiense. Con esta datación inicial comienza, en su opinión, todo el proceso pictográfico:

a) Fase naturalista, con un primer período de figuras del tipo de los toros de Albarracín, y un segundo período con pinturas de los ciervos de Calapatá.

b) Fase estilizada-estática.

c) Fase estilizada-dinámica.

d) Fase de transición a la pintura esquemática.

Mientras que en la primera fase, de Ripoll, sólo encontramos representaciones faunísticas de mediano y gran tamaño, en la segunda y tercera se incorpora la figura humana conservándose el naturalismo de los animales, pero de tamaño más reducido, y culminando con las abigarradas escenas del Maestrazgo y del Bajo Aragón en la fase c) estilizadadinámica. Estas dos fases habrían coincidido con la llegada de los primeros neolíticos. Su última fase de transición correspondería a la neolitización con fuertes penetraciones en el sudeste y en Andalucía, con abundancia de signos esquemáticos y con tendencia a la esquematización.

En cambio A. Beltrán, basándose esencialmente en las fases de Ripoll, propone un marco cronológico, también con 4 fases que se enmarcarían después del 7000 hasta el 1200/1000 a. C., mostrándo pequeñas modificaciones, respecto al anterior. Su I fase, contemporánea del Epipaleolítico sería de tradición auriñaco-perigordiense, sugeriendo en esta fase, la existencia de signos geométricos y figuras de aire esquemático. En su II fase, plena, encontramos abundancia de ciervos y cabras, desaparición progresiva de los toros y la aparición de la figura humana escasamente naturalista, datándola a partir del 
4000 , señalando que uno de los núcleos más claros estaría representado en el panel central de las grandes figuras de Cueva Remigia. Su fase III, de desarrollo, que coincide con la c) de Ripoll, la sitúa entre el 3500 al 2000 a. C., contemporáneo del Neolítico de los llanos litorales. Aquí encontramos a la figura humana, lanzada a la carrera y con gran movimiento de los animales. Para A. Beltrán la fase final, estaría señalada por una vuelta al estatismo y a la tendencia esquematizante, introduce la agricultura con palos de cavar y la domesticación de los animales, la cual debe datarse en su opinión después del 2000 hasta el 1200 a. C., es decir, una fase comprendida entre el Eneolítico y el Bronce I. Posteriormente este autor ha ampliado su cuadro cronológico, con una fase que denomina pre-levantina, antes del 6000 a. C. y en donde incluye antropomorfos, signos fantásticos, temas geométricos y esquemáticos, que como veremos más adelante, otros autores han propuesto su correlación con el Neolítio Antiguo (Beltrán 1968 y 1986).

También cabe señalar los trabajos de otros autores como los de L. Pericot, que aceptando un entronque con el Paleolítico y un desarrollo hasta el Neolítico, propusieron estudiar la relación de este arte con el del sudeste de Francia, el italiano y el africano, y en especial las posibles influencias africanas en España o viceversa, para explicar la aparición de la figura humana en el arte rupestre (Peri$\cot 1964)$.

Sincrónicamente a los trabajos de E. Ripoll y A. Beltrán, aparecen los de F. Jordá, que apunta una cronología más moderna para todo este proceso pictográfico, considerando sincrónico el proceso del arte naturalista, con el esquemático abstracto. Para este autor ambos estilos tienen sus raíces en las culturas agrícolas ganaderas de los pueblos del Mediterráneo oriental, los cuales habrían llegado a las costas levantinas en dos oleadas. La primera con la cerámica cardial y la agricultura de gramíneas, que se instalaría preferentemente en todo nuestro Levante y la segunda, con cerámica sin decorar se dirigiría hacia el sur (Jordá 1966).

Años después, J. Fortea amparándose en las observaciones de A. Beltrán sobre la existencia de antiguas figuras geométricas y esquemáticas por debajo de representaciones naturalistas, desarrolla una nueva teoría sobre la existencia de un arte-lineal geométrico relacionado con las placas de la Cueva de la Cocina de edad Epipaleolítica. Esta fase anterior a las formas naturalistas, le llevaría a considerar a estas últimas «...en su mayoría corresponden a un Neolítico y al Bronce» (Fortea 1974).

El descubrimiento de un nuevo tipo de manifestaciones en la provincia de Alicante denominado como «macroesquemático» y ya conocido bajo los ciervos de la cueva de la Sarga, que en opinión de Beltrán, representarían su fase pre-levantina, epipaleolítica, han puesto de relieve la relación con las decoraciones de la cerámica cardial de la Cova de l'Or, y demostrando que los ciervos naturalistas existentes en la Sarga, de mediano tamaño, serían posteriores o coetáneos al Neolítico Antiguo (Martí y Cabanillas 1987).

A pesar de todos estos nuevos hallazgos y de la polémica que han suscitado, continúan todavía los defensores de una cronología paleolítica, para las manifestaciones naturalistas, señalemos a Lya Dams que para todo este proceso establece cuatro fases que engloba entre el $11000 / 10000$ y el $4000 \mathrm{a}$. C. (Dams 1984). De forma similar, pero retrocediendo todo el proceso 1.000 años, encontramos la cronología de J. Aparicio y otros (Aparicio, Meseguer y Rubio 1982).

Por el contrario otros trabajos más recientes basados en el análisis etnográfico, han situado estas manifestaciones en la transición del Neolítico y el Eneolítico. Este estudio centra la filiación cronocultural, en las puntas de flechas que divide en varios tipos, señalando que en Cueva Remigia, existe el astil recto, la flecha foliácea, con tendencia romboidal y la flecha con forma triangular. En nuestra opinión, la autora de este trabajo F. Galiana confunde en la mayoría de los casos, la punta de la flecha por la emplumadura. Este detalle, ya fue señalado por H. Obermaier y P. Wernert al estudiar las pinturas de La Valltorta, los cuales remarcaron que esta forma lanceolada, o romboidal correspondia a la emplumadura y no a la flecha (Obermaier y Wernert 1915).

Por lo que respecta a la Cova Remigia, debemos remitirnos en primer lugar, a la monografía realizada por Porcar, Obermaier y Breuil, que plantearon para este friso una cronología paleolítica principalmente por la presencia, en su opinión, de un alce y un uro (Porcar, Obermaier y Breuil 1935). Cabe decir, que estos ejemplares ya fueron en parte desmentidos por M. Almagro y como hemos podido comprobar en nuestra revisión, se trata en el primer caso de un posible bóvido repintado sobre otra figura, tal vez un ciervo muy deteriorado y por lo tanto dudoso y polémico; en el segundo caso, el uro, 
representa un cérvido cuyas orejas fueron confundidas con los cuerpos de un bóvido. Por lo tanto, estos dos ejemplares quedan excluidos de la fauna cuaternaria.

J. Porcar, dedicó diversos trabajos a estas pinturas y estableció dos fases: la primera caracterizada por «conjunto preciosista estátil, realista, arte imitativo animalista. Cada figura ha sido concebida dentro de un contorno y perfil de trazo fino...»» mientras que la segunda fase corresponde a «...estilos varios que tienden a un reducido tamaño de miniatura, predominando sobre la fauna la representación de la figura humana, todo un torbellino de escenas...» (Porcar 1943). Esta segunda fase es denominada por Porcar como impresionista de concepto descriptivo, trazo caligráfico y de impresión directa.

En las anotaciones cronológicas que dio E. Ripoll sobre el vecino conjunto del Cingle de la Mola Remigia, encontramos como capa más antigua, la fase de los grandes bóvidos aislados y estáticos seguidos de otra fase de bóvidos más pequeños asociados a figuras humanas de gran tamaño, todavía no estilizadas. A éstos le sigue otra fase estilizada naturalista de gran tamaño, cuyos mejores ejemplos, señala los de la Cova Remigia; posteriormente a éstos sitúa los arqueros dinámicos estilizados que en su opinión caracterizan el «Arte Levantino» clásico, señalando como ejemplos la escena de jabalíes de la cavidad $\mathrm{V}$, en donde observa la doble escena integrada por dos grupos, la primera formada por figuras orientadas hacia la izquierda, con un realismo dinámico, se entremezclan con otra escena realizada posteriormente con figuras más esquemáticas y de trazo suelto. Con este esquema, observamos como E. Ripoll sitúa a la figura del gran arquero de la cavidad $V$, en su fase b) los arqueros de realismo dinámico en la fase c) y por último a los arqueros más esquemáticos de trazo suelto a los comienzos de la fase d). Por lo tanto la secuencia de Cueva Remigia, se iniciaría en su fase b) contemporánea del Neolítico hasta la fase d) de transición hacia el esquematismo, anotando la ausencia de la fase a) sólo existente en el Cingle de la Mola Remigia (Ripoll 1963).

En 1981, M. Mesado realiza un trabajo sobre algunos materiales arqueológicos de la Cova del Mas d'en Llorenç y aprovecha la ocasión para dar a conocer su opinión sobre las fases del conjunto de Cova Remigia «Ya que en la monografía de esta cueva no se ha hecho relación a esta problemática vol- vemos sobre las fases estilísticas sobre Cova Remigia, pues los diversos estilos son bien claros». Este autor establece tres fases que compara con las de E. Ripoll y A. Beltrán, la fase I, estática (se corresponde con la c) de Ripoll y la II) de Beltrán. Creemos que el autor se confunde al compararlas con la c) de Ripol, pues se trata de su fase estilizadadinámica. Su fase II, dinámica (se corresponde con la fase d) de Ripoll y III) de Beltrán) y por último su fase III, de microfiguras que corresponde a la fase IV de Beltrán. Según este autor, esta fase «Se generaliza una nueva iconografía: «trepadores», «arboriformes», «brujos», «panoplias» «tocados bicornes», etc. M. Mesado basa su cronología en la comparación de los denominados «envases», al parecer un cesto redondo con asas y algunas bolsas, concretamente, la del cazador $n .^{\circ} 56$, de la cavidad V, que en su opinión corresponden a cerámicas, posiblemente recubiertas con piel, con las que establece un paralelismo con las neolíticas de la Cova de l'Or de Beniarrés (Mesado 1981). Este autor, propone una cronología mesolítica en sus inicios,con un auge en el Neolítico, situando a las figuras cestosomáticas, es decir,la figura del gran arquero, en el horizonte neolítico de las cerámicas incisas de la Cova Fosca. Desconocemos si algún pueblo de cazadoresrecolectores ha utilizado recipientes cerámicos, como bolsas colgantes durante las cacerías, pues aunque la similitud entre bolsas y cerámicas, acostumbra a ser evidente, esto no presupone que lo que transportan los cazadores sean recipientes cerámicos, nada prácticos en este tipo de actividades.

Desde 1984 Carmen Olaria y Francesc Gusi han intentado establecer una relación entre la Cova Remigia y el resto de abrigos con arte rupestre con el yacimiento de Cova Fosca, pues en su opinión no puede considerarse como casual la proximidad de todos estos yacimientos. Las evidencias arqueológicas encontradas en Cova Fosca, demuestran que los habitantes de esta cueva se dedicaron a la caza de ciervos, corzos, jabalíes y otros animales que aparecen en sus tres fases ubicadas dentro de un período meso-eneolítico y al que sitúan la ejecución de los frisos. Según las dataciones obtenidas en este yacimiento el período estaría comprendido entre el VIII milenio y la primera mitad del VI a. C. (Olaria y Gusi 1984). Esta cronología ha sido defendida nuevamente en la tesis de licenciatura de C. Olaria sobre Cova Fosca (Olaria 1988).

No cabe la menor duda de que entre los niveles de Cova Fosca y las fases pictográficas de Cova 
Remigia debe existir algún tipo de relación, aunque debemos ser muy prudentes en establecer relaciones entre las fases de ambos conjuntos. Será necesario un mejor conocimiento de los datos arqueológicos y confirmar las distintas fases pictográficas que hemos propuesto.

\section{CONCLUSIONES}

Tras el análisis de los distintos aspectos que comprende el friso o mural de Cova Remigia, podemos concluir que este mural integrado por $759 \mathrm{fi}-$ guras, comprende una temática, basada en actividades de caza y otras relacionadas con ésta. Las especies capturadas son predominantemente los cápridos y los suidos, seguidos de los ciervos y los bóvidos; el resto de la temática comprende una diversa iconografía entre la que destaca, los personajes flechados, sacrificados, o ejecutados de los que existen 5 ejemplos.

Los colores utilizados pertenecen a las gamas del rojo-castaño, castaño-rojizo, minoritariamente el negro y unas pocas figuras de color rosado y anaranjado. El estudio del color, ha sido poco válido para establecer la cronología relativa del friso, pues estilos similares o idénticos aparecen pintados en colores distintos y estilos dispares muestran los mismos colores.

Tipológicamente predominan las figuras humanas sobre las de animales, y estilísticamente, mientras que las representaciones faunísticas mantienen formas proporcionadas-naturalistas, las figuras humanas pertenecen a tipos desproporcionados-semiesquemáticos, con variantes muy esquematizadas de pequeño tamaño, tipos con rasgos naturalistas, principalmente en las piernas de mediano y gran tamaño y unas pocas figuras proporcionadas-naturalistas de mediano tamaño.

Desde un punto de vista técnico las figuras de animales han sido ejecutadas mediante un silueteado inicial y recubierto en una tinta plana, mientras que unos pocos ejemplares sólo han sido realizados con la técnica del silueteado. En cambio las figuras humanas muestran como técnica predominando el trazo simple, seguido de la tinta plana. El tamaño de los animales oscila entre los 2,1 hasta los 31,5 $\mathrm{cm}$. siendo el ejemplar más pequeño la figura de un pequeño carnívoro y la de mayor tamaño la imagen de un ciervo. Por lo que respecta a las figuras humanas los tamaños más pequeños lo integran las formas más esquemáticas de trazo simple que oscilan alrededor de $2 \mathrm{~cm}$., mientras que las de mayor tamaño lo forman los tipos desproporcionados semiesquemáticos, con rasgos naturalistas principalmente en las piernas cuya mayor figura alcanza los 53,5 $\mathrm{cm}$.

La superposición estilística apoyada en cierto modo por la característica cromática ha constituido la base de nuestra cronología relativa que invierte las hipotéticas fases establecidas por E. Ripoll y A. Beltrán, pero que encajan en cierto modo con las que había propuesto $\mathrm{H}$. Breuil, para el conjunto de Minateda ya que en la capa inferior observó la existencia de figuras humanas muy esquemáticas de pequeño tamaño en rojo claro. Esta observación, que no fue lo suficientemente valorada por E. Ripoll y A. Beltrán, sí fue comentada por L. Pericot, que al tratar los problemas del arte levantino señaló: «...el conjunto de Minateda es de extraordinaria importancia. Sobre todo, la afirmación del abate Breuil, de que la capa inferior que él observó es la de unos seres humanos muy esquemáticos en un color rojo claro, significaría, si lo aceptamos, que ya desde el primer momento de su aparición, los pintores levantinos contaron con la representación humana en forma esquemática» (Pericot 1964).

Según los registros obtenidos en las superposiciones, y en los repintes se han podido comprobar la existencia de 4 grandes momentos que hemos dividido en 7 fases por las diferencias estilísticas. En la fase más antigua (fase I), los animales de pequeño y mediano tamaño muestran formas proporcionadas naturalistas y aparecen asociadas a figuras humanas de pequeño tamaño y semi-esquemáticas, todas ellas en color negro. Cabe señalar que ya desde el primer momento las figuras muestran movimiento y dinamismo. La fase II, se manifiesta por figuras relativamente similares, también de pequeño y mediano tamaño en colores predominantemente rojizos y castaños en donde también hay que incluir de oscuros y negruzcos. La fase III, ha sido subdividida en tres momentos, principalmente por la distinta anatomía de las figuras. En las figuras humanas se observa un cambio substancial, consistente en el mayor relieve de las piernas que alcanzan formas estilizadas con rasgos naturalistas, y que constituyen la produccion más importante del mural, con escenas sumamente complejas, en donde el movimiento alcanza su máximo esplendor, con la cacería de algunos jabalíes, cápridos y bóvidos. En la fase IV, reaparece un nuevo momento de figuras hu- 
manas semi-esquemáticas, que muestran la mayoría de ellas, un ensanchamiento del tronco, piernas rectas y delgadas; mientras que los animales continúan manteniendo formas más o menos naturalistas con cierta estilización. En este momento encontramos una predominancia de los jabalíes. La fase $\mathrm{V}$, constituye el momento en que la figura humana alcanza, la máxima estilización del tronco, conservando el realismo de las piernas y debería suceder a la fase III, pero la superposición del gran arquero sobre una figura de la fase IV, coloca a este personaje, junto con el gran ciervo, con el que forma escena, en un momento muy avanzado del proceso pictográfico de Cova Remigia, invirtiendo de este modo, las fases que habían sido sugeridas hipotéticamente por otros autores. La fase VI, representa la pervivencia de formas precedentes que fueron añadidas posteriormente, la mayoría de ellas son semi-esquemáticas o esquemáticas. Para la última fase VII, no poseemos ningún tipo de superposición con relación a otras fases, pero su ubicación parece señalar que fueron ejecutadas en un momento final. Todas ellas muestran rasgos semi-esquemáticos o esquemáticos.

Según las fases que hemos podido establecer, se entrevé a grandes rasgos un primer momento de pequeñas figuras, muy esquemáticas y animales naturalistas principalmente cápridos (fases I y II). A este primer momento le seguiría el gran bloque de figuras sumamente variadas, muy dinámicas, con rasgos semi-esquemáticos y naturalistas, en donde predominan los jabalíes sobre el resto de las especies (fases III-IV-V) y por último un grupo de figuras generalmente pequeñas que se sitúan en zonas limítrofes semi-esquemáticas y esquemáticas (fase VI y VII).

No cabe duda, de que es difícil, sino imposible, encajar estas fases con las propuestas por E. Ripoll y A. Beltrán, pero como bien dicen estos autores son meras hipótesis de trabajo, «...pero no creemos que no puedan ser calificadas de otra manera las teorías que se van presentando acerca de estos problemas... Opinamos que, a la espera de tales datos que algún día llegaremos a poseer, hay que seguir trabajando con las cronologías relativas deducidas de las superposiciones, los caracteres estilísticos y los paralelos de estas obras de arte» (Ripoll 1966).

Indicaremos al respecto, la composición faunística de l'Abric de laTenalla, estudiado por R. Viñas y M. K. Bader, en donde se comprueba una se- cuencia evolutiva que parte de una pequeña escena con una figura humana dinámica, perteneciente a la fase estilizada-dinámica de Ripoll o III de Beltrán, sobre la cual se ejecutaron un grupo de ciervos de tipo Calapatá, es decir de la fase a) o b) de Ripoll y I-II de Beltrán. Como vemos contradice las citadas fases y se demuestra que sobre pequeñas figuras dinámicas se pintaron ciervos de mayor tamaño tipo Calapatá. Este hecho demuestra la existencia de ciervos de mediano y gran tamaño estáticos y naturalistas sobre fases de figuras más pequeñas, lo cual viene a indicar que los ciervos naturalistas se realizaron a lo largo de todo el proceso pictográfico (Viñas y Bader 1986-87).

Por último y por lo que respecta a la filiación crono-cultural las evidencias arqueológicas señalan una vez más un contexto Epipaleolítico, Neolítico y Bronce para el proceso pictográfico de este fenómeno socio-cultural.

\section{BIBLIOGRAFIA}

ALMAGRO BASCH, Martín: El covacho con pinturas rupestres de Cogul (Lérida), Instituto de Estudios Ilerdenses, Lérida, 1952, $92 \mathrm{p}$.

APARICIO, J.; MESEGUER, V.; RUBIO F.: El primer arte valenciano, II, «El Arte Rupestre Levantino», Serie Popular, Conozca su patrimonio histórico-artístico, n. ${ }^{\circ} 2$, Valencia $1982,74 \mathrm{p}$.

BELTRÁN MARTÍNEZ, A.: El arte rupestre levantino, Monografías Arqueológicas, 1968, $256 \mathrm{p}$.

- El arte rupestre en la provincia de Teruel, «Cartillas turolenses», n. ${ }^{\circ} 5,1986,59 \mathrm{p}$.

BREUIL, H.: Les roches peintes de Minateda (Albacete), Rev. L'Anthropoloie, T. XXX, Paris 1920, 50 p.

DAMS, Lya: Les peintures rupestres du Levant Espagnol, París 1984, $303 \mathrm{p}$.

ESTÉVEZ GONZÁLEZ, F.: Probable significado de unas pinturas rupestres del Maestrazgo, Cuadernos de Prehistoria y Arqueología Castellonenses, 1, Castellón 1974, p. 9-18.

FRANCIA GALIANA, María: Contribución al arte rupestre levantino: análisis etnográfico de las figuras antropomorfas, «LUCENTUM» IV, 1985, Anales de la Universidad de Alicante Prehistoria, Arqueología e Historia Antigua, Alicante 1986 , p. $55-87$.

FORTEA, J.: Los complejos microlaminares y geométricos del Epipaleolítico mediterráneo español, «Memorias del Seminario de Prehistoria y Arqueología», n. ${ }^{\circ}$ 4, Salamanca 1973, p. $159-198$.

- Algunas Aportaciones a los Problemas del Arte Levantino, «Zephyrus XXV», 1974, p. 225-257.

FORTEA, F.: Entorno a la cronología relativa del inicio del arte levantino (Avance sobre las pinturas rupestres de la Cocina) «Papeles del Laboratorio de Arqueología de Valencia», n. ${ }^{\circ} 11$, Valencia 1975, p. 185-197. 
HERNÁNDEZ-PACHECO, F.: Las pinturas prehistóricas de las Cuevas de la Araña (Valencia). Evolución del arte rupestre de España «Comisión de Investigaciones Paleontológicas», Memoria n. ${ }^{\circ}$ 34, Madrid 1924, p. 161-173.

JORDÁ, F.: Notas para una revisión de la cronología del Arte Rupestre Levantino, Zephyrus XVII, Salamanca, 1966, p. 47-76.

JORDÁ CERDÁ, F.: Sobre la cronologia del Arte Rupestre Levantino, XII, Congreso Nacional de Arqueología, Jaén 1978, Zaragoza 1973, p. 85-99.

MARTÍ, B.: El Neolítico en la Península Ibérica. Papeles del Laboratorio de Arqueología-Saguntum, 13, Valencia 1978, p. 59-98.

MARTÍ OLIVER, B.; JUAN CABANILLES, J.: EI Neolítico Valencià, Els primers agricultors i ramaders, Servei d'Investigació Prehistórica de la Diputació de València, València 1987, 146 p.

MESADO OLIVER. M.: La Cova del Mas d'en Llorenç y el Arte Prehistórico del Barranc de la Gasulla, «Archivo de prehistoria levantina», vol. XVI, Valencia 1981, p. 281-305.

OLARIA, C.; GUSI, F.: Cueva Fosca. Nuevas fechas de C-14 para el Neolítico mediterráneo de la Península Ibérica. C-14 y Prehistoria de la Península Ibérica, Serie Universitaria, Madrid 1978.

OLARIA PUYOLES, C.; GUSI JENER, F.: Estudio del territorio para la comprensión del hábitat prehistórico: Un ejemplo del Neolítico Antiguo, «Arqueología Espacial», n. ${ }^{\circ} 3$, Teruel 1984, p. 41-50.

OLARIA, C.: Un asentamiento meso-neolítico, de cazadores y pastores en la serrania del Alto Maestrazgo, Monografías de Prehistoria y Arqueología Castellonense, n. ${ }^{\circ} 3$, Castellón 1988, 424 p.

OBERMAIER, H. y WERNERT, P.: Las pinturas rupestres del Barranco de la Valltorta (Castellón), "C.I.P.P.», Memoria n. ${ }^{\circ}$ 23, Madrid 1919, 134 p.

OBERMAIER, H.: Las pinturas rupestres del Barranco de Gasulla (provincia de Castellón), en Investigación y Progreso, año $X, n .^{\circ}$, Madrid 1936, p. 1-9.

PALLARÉS, M.: Exploració dels jaciments prehistorics de la Valltorta, Anuari del Institut d'Estudis Catalans, $n .^{\circ} 6$, Barcelona 1915-1920, p. 454-457.

PERICOT, L.: Sobre algunos problemas del arte rupestre del Levante español. Prehistoric Art of the Wester Mediterranean and the Sahara edited by L. Pericot and E. Ripoll, Viking Fund Publication in Anthropology, n. ${ }^{\circ} 39$, New York 1964, p. $151-156$.

PORCAR RIPOLLÉS, J.: Pintures rupestres del Barranc de Gasulla, «B.S.C.C.», XI, Castellón 1934, p. 343-347.

- Noves pintures rupestres en el Terme d'Ares, «B.S.C.C.», XVI, Castellón 1935, p. 30-32.

PORCAR, J.; OBERMAIER, H.; BREUIL, H.: Excavaciones en la Cueva Remigia (Castellón). Memoria de la Junta Superior de Excavaciones, 136, Madrid 1935, 95 p.

PORCAR RIPOLLÉS, J.: El trazo por impresión directa y el trazo caligráfico en el arte rupestre de Ares del Maestre. «B.S.C.C.», XVIII, Castellón 1942, p. 262-266.
- Sobre las pinturas rupestres de Ares del Maestre, «B.S.C.C.»,XVIII, Castellón, 1943, p. 15-16.

- El valor expresivo de las oblicuas en el arte rupestre del Maestrazgo, «B.S.C.C.», XX, Castellón 1944, p.7-16.

- Pinturas rupestres arrancadas de Cueva Remigia «B.S.C.C.», XIX, Castellón 1944, p. 35-182.

- Iconografía rupestre de la Gasulla y Valltorta. Danza de arqueros ante figuras humanas sacrificadas. «B.S.C.C.», XXI, Castellón 1945, p. 145-152.

- Iconografía rupestre de la Gasulla y Valltorta, Escenas bélicas, «B.S.C.C.», XXII, Castellón 1946, p. 48-60.

- Iconografía rupestre de la Gasulla y Valltorta. Representación pictográfica del toro. Sus características. Particularidades que ofrece. «B.S.C.C.», XXIII, Castellón 1947, p. 314-324.

- Iconografía rupestre de Gasulla. Representación de insectos. Características y particularidades que ofrecen. «B.S.C.C.», XXV, Castellón 1949, p. 169-182.

- Monumentos histórico-artísticos. Las pinturas rupestres de Ares «Revista Penyagolosa», n. ${ }^{\circ}$, Diputación Provincial de Castellón de la Plana, 1955.

- Impresiones sobre el arte rupestre existente en el Maestrazgo. Prehistoric Art of the Wester Mediterranean and the Sahara, edited by L. Pericot and E. Ripoll, Viking Fund Publications in Anthopology, n. ${ }^{\circ} 39$, New York 1964, p. 159-164.

- Un cens de població rupestre de les pintures del Barranc de la Gasulla, «B.S.C.C.» LI, Castellón 1975, p. 4-9.

RIPOLL PERELLÓ, E.: Para una cronología relativa de las pinturas rupestres del Levante español, en Festschrift für Lothar Zotz Erlangen, 1960, p. 447-456.

- Pinturas Rupestres de la Gasulla (Castellón), Monografía de Arte Rupestre, «Arte Levantino», n. ${ }^{\circ}$ 2, Barcelona 1963 , 59 p.

- Cuestioes entorno a la cronología del arte rupestre postpaleolítico en la Península Ibérica, «Symposium de Arte Rupestre», Barcelona 1968, p. 165-192.

- Para una cronología relativa del arte levantino español, Prehistoric Art of the Weter Mediterranean and the Sahara, edited by L. Pericot and E. Ripoll, Viking Fund Pubications in Anthropology, n. ${ }^{\circ}$ 39, New York 1964, p. 167-173.

VIÑAS, R.; SARRIÁ, E.: Representaciones faunísticas en la pintura levantina del término de Ares del Maestre (Castellón de la Plana), Cuadernos de Prehistoria y Arqueología Castellonense, n. ${ }^{\circ}$ 5, Castellón 1978, p. 143-161.

VIÑAS, R.; SARRIÁ, E.; MONZONIS, F.: Nuevas manifestaciones de arte rupestre en el Maestrazgo (Castellón de la Plana). Cuadernos de Prehistoria y Arqueologia Castellonense, n. ${ }^{\circ}$ 6, Castellón 1979, p. 97-120.

VIÑAS, R; BADER, M.; BADER, K.: Una composición faunística en el «Abric de la Tenalla», La Pobla de Benifasá (Castellón), Rev. Bajo Aragón Prehistoria, I. Congreso Internacional de Arte Rupestre, vol. VII-VIII, Caspe (Zaragoza), 1986-87, p. 359-368.

VIÑAS, R. y RUBIO, A.: Un nuevo ejemplo de figura flechada en el conjunto de la Valltorta (Castellón) (en prensa). 